\title{
SAVANNAH RIVER SITE \\ 1996 Epidemiologic Surveillance Report
}

Questions or comments about this report or the Epidemiologic Surveillance Program may be directed to:

Dr. Cliff Strader at cliff.strader@eh.doe.gov or Dr. Bonnie Richter at bonnie.richter@eh.doe.gov

United States Department of Energy

Office of Epidemiologic Studies

Mail Stop: 270CC/EH-62

19901 Germantown Road

Germantown, MD 20874-1290

Additional information about the Department of Energy's Office of Epidemiologic Studies, the Epidemiologic Surveillance Program, and annual reports for DOE sites participating in this program can be found at:

http://www.eh.doe.gov/epi 


\section{DISCLAIMER}

This report was prepared as an account of work sponsored by an agency of the United States Government. Neither the United States Government nor any agency thereof, nor any of their employees, make any warranty, express or implied, or assumes any legal liability or responsibility for the accuracy, completeness, or usefulness of any information, apparatus, product, or process disclosed, or represents that its use would not infringe privately owned rights. Reference herein to any specific commercial product, process, or service by trade name, trademark, manufacturer, or otherwise does not necessarily constitute or imply its endorsement, recommendation, or favoring by the United States Government or any agency thereof. The views and opinions of authors expressed herein do not necessarily state or reflect those of the United States Government or any agency thereof. 


\section{DISCLAIMER}

Portions of this document may be illegible in electronic image products. Images are produced from the best available original document. 


\section{Savannah River Site 1996 \\ AT A GLANCE}

Eight percent of the workers reported at least one absence in 1996, unchanged from the 1995 percentage.

For any given age group, the absence rate among women was at least twice that of men.

The dramatic decline in the number of 5-day absences seen from 1994 to 1995 did not continue into 1996. The number of absences reported in 1996 was almost identical to the number reported in 1995.

The three leading diagnostic categories among women remained unchanged from 1995. Respiratory, genitourinary, and muscle and skeletal conditions accounted for 48 percent of all reported diagnoses among women.

Two of the three most frequently reported diagnoses were the same for men and women. Among men, 69 percent of all reported diagnoses were due to respiratory conditions, muscle and skeletal conditions, digestive conditions, injuries, and heart and circulatory conditions.

We observed no evidence of an excess of any particular type of cancer, nor any evidence that a particular occupational group had an excess of reported cancer.

The number of workers with at least one OSHA-recordable event in 1996 increased 54 percent compared with the number of workers in 1995. This doubling may to some degree reflect improved reporting of OSHA data in 1996; 1995 was the first year in which Savannah River Site submitted OSHA data to the Epidemiologic Surveillance Program.

The rate of OSHA-recordable events was about the same for women and men in 1996. The occurrence of OSHA-recordable injuries did not appear related to age.

Sprains and strains, as well as open wounds, were the most common types of OSHA-recordable injuries among both men and women.

Crafts and Manual Labor workers had an overall occupational injury risk at least 7 times greater than the other occupational groups. 
Introduction 1

Site Overview .2

The Savannah River Site

Work Force 1996

The Work Force by Gender and Age ..3

The Work Force by Job

Category and Gender .3

\section{Number and Length of}

Absences 4

Absence Rate by Gender

and Age .4

Number of Days Absent by

Gender and Age

Absence Rate by Job

Category and Gender. .5

Average Duration of Absence by Job Category and Gender ......6

\section{Diagnostic Categories}

Number of Diagnoses and Lost Calendar Days by Diagnostic Category (Categorized by ICD-9-CM) and Gender. .7
Most Frequently Reported Diagnoses by Job Category and Gender 9

Rates of Disease Occurrence. 9

Illness and Injury Rates by Job Category, Gender, and Age

Time Trends. 12

Age-Adjusted Rates for All Diagnoses Combined Among Women and Men by Job Category from 1994 to 1996.

Age-Adjusted Rates for Selected Diagnostic Categories for Men and Women from 1994 to 1996 . 14

\section{Sentinel Health Events}

for Occupations 15

Characteristics of SHEOs by Gender. 15

\section{Disabilities Among Active}

Workers 16

\section{Deaths Among Active} Workers 16 
OSHA-Recordable Events 16

OSHA-Recordable Events by

Gender and Age

OSHA-Recordable Events by Job Category and Gender

Diagnostic and Accident

Categories for OSHA-

Recordable Events

OSHA-Recordable Diagnoses

by Diagnostic Category

and Gender

OSHA-Recordable Accidents

by Type and Gender

Rates of OSHA-

Recordable Events

OSHA-Recordable Rates by

Age and Job Categories

Among Women, All Diagnoses

Combined

OSHA-recordable Rates by Age and Job Categories Among Men, All Diagnoses

Combined
Time Trends for OSHA-

Recordable Events

Glossary 20

\section{Explanation of Diagnostic}

Categories

ICD-9-CM Codes 22 


\section{Introduction}

The U.S. Department of Energy's (DOE) commitment to assuring the health and safety of its workers includes the conduct of epidemiologic surveillance activities that provide an early warning system for health problems among workers. The Epidemiologic Surveillance

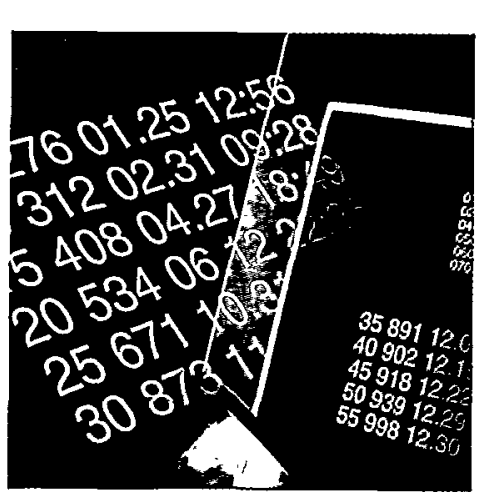

Program

monitors illnesses and health conditions that result in an absence of five or more consecutive workdays, occupational injuries and illnesses, and disabilities and deaths among current workers.

Epidemiologic Surveillance has been conducted at Savannah River Site (SRS) since 1994, and as a pilot project from 1992. This report provides a summary of epidemiologic surveillance data collected from SRS from January 1, 1996 through December 31, 1996. The data were collected by a coordinator at SRS and submitted to the Epidemiologic Surveillance Data Center located at Oak Ridge Institute for Science and Education, where quality control procedures and preliminary data analyses were carried out. The analyses were interpreted and the final report prepared by the DOE Office of Epidemiologic Studies.

The Epidemiologic Surveillance report for SRS has been redesigned for 1996. The information in this report provides highlights of the data analyses conducted. Surveillance reports and additional supporting tables are posted on the DOE Office of Epidemiologic Studies' Web Site http://www.eh.doe.gov/ epi/, or are available by request.

The main sections of the report include: work force characteristics; absences due to injury or

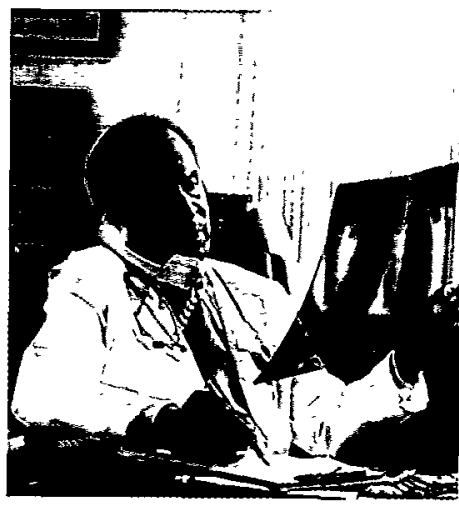
illness lasting five or more consecutive workdays; workplace illnesses, injuries, and deaths that were reportable to the Occupational Safety and Health Administration ("OSHA-recordable" events); and disabilities and deaths among current workers. The 1996 report includes a new section on time trends that provides comparative information on the health of the work force from 1994 through 1996.

\section{Note: In the figures and calculations that follow, percentages have been rounded to the nearest whole number.}

DOE sites vary by mission, function, job classification, and worker exposures. Comparisons of SRS with other DOE sites should be made with caution. In addition, many factors can affect the completeness and accuracy of health information reported at the sites, thereby affecting the observed patterns of illness and injury.

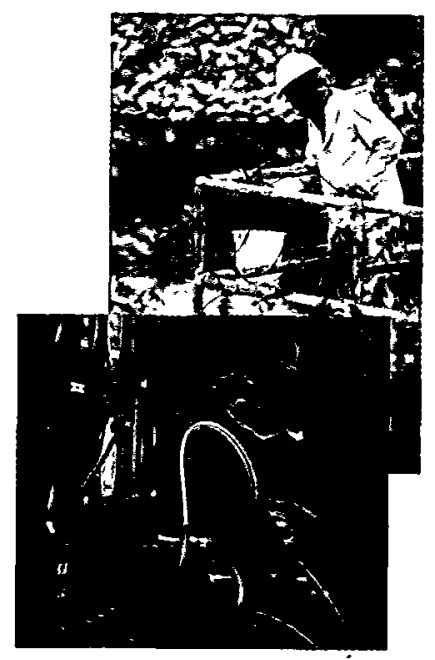




\section{Site Overview}

SRS is a 320-square-mile facility located on the Savannah River near Aiken, South Carolina, and Augusta, Georgia. It is owned by the U.S. Department of Energy and operated by the Westinghouse Savannah River Company. The facility was constructed during the 1950s and produced nuclear weapons materials (tritium and plutonium-239) for the United States defense program from that time through the 1980s. The years of weapons materials production resulted in unusable byproducts such as

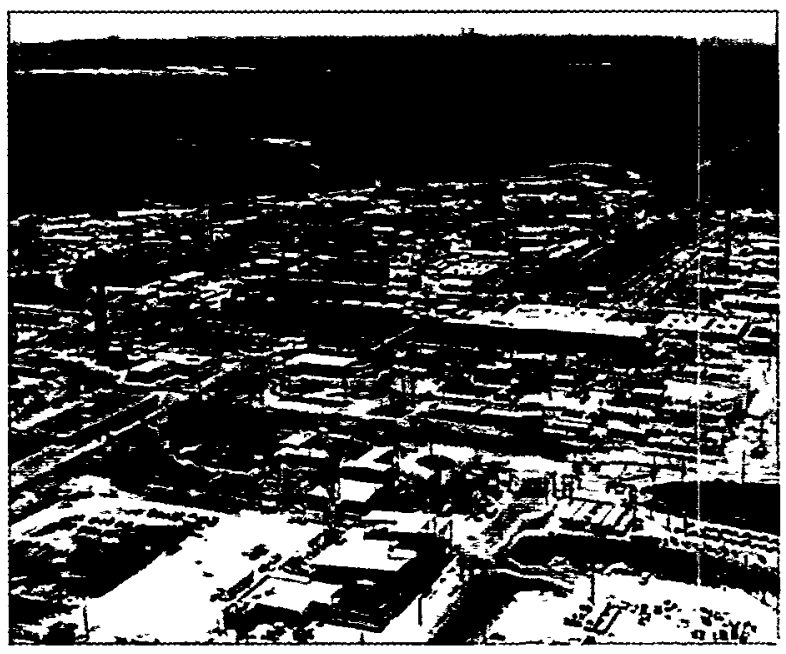

intensely radioactive waste, low-level liquid and solid radioactive wastes, transuranic waste, hazardous waste, and mixed wastes.

After the end of the Cold War, the mission for SRS changed from nuclear materials production to environmental restoration and waste management. All five of the original production reactors are permanently shut down. There are over 400 inactive waste and groundwater units in the site's environmental restoration program. This work is expected to take decades to complete. Decontamination and decommissioning of surplus

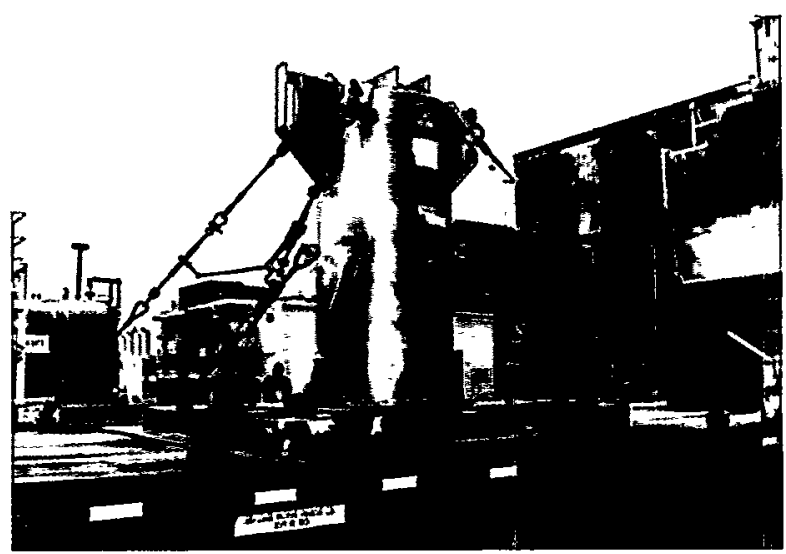

facilities is also being conducted, with more than 600 facilities presently being assessed.

Part of the site's mission is to recycle and reload tritium to keep the nation's supply of nuclear weapons ready. SRS is the nation's only source for recycling tritium from reservoirs of nuclear weapons no longer in service. This process allows the United States to stretch its tritium supplies. The site is also focusing on national security work, economic development and technology transfer initiatives, and environmental and waste management activities.

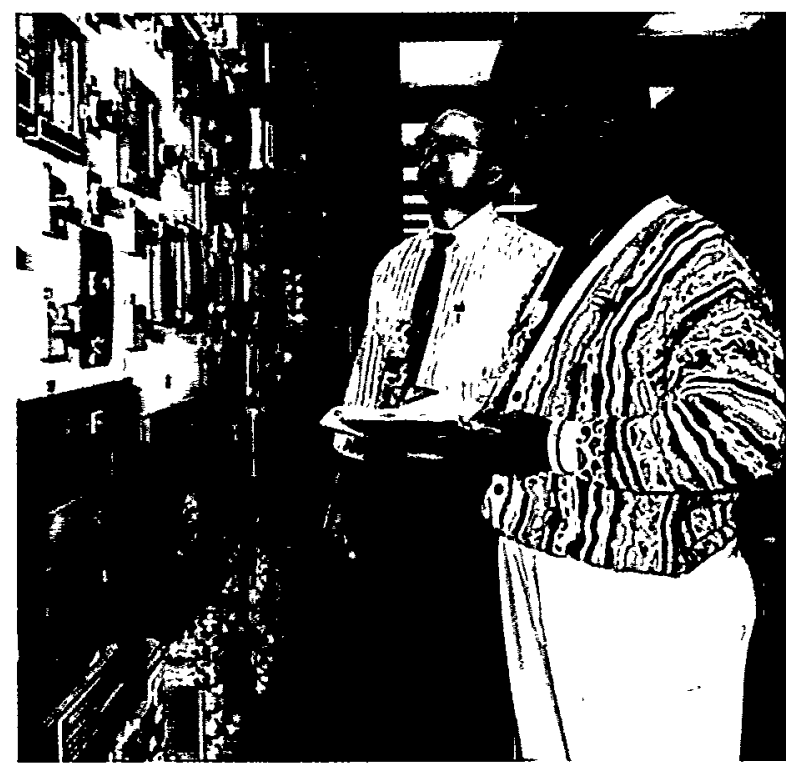




\section{The Savannah River Site Work Force - 1996}

A total of 14,711 SRS employees were included in epidemiologic surveillance in 1996, 408 fewer workers than were present in 1995. The age and gender distribution of the 1996 work force is shown in Figure 1.

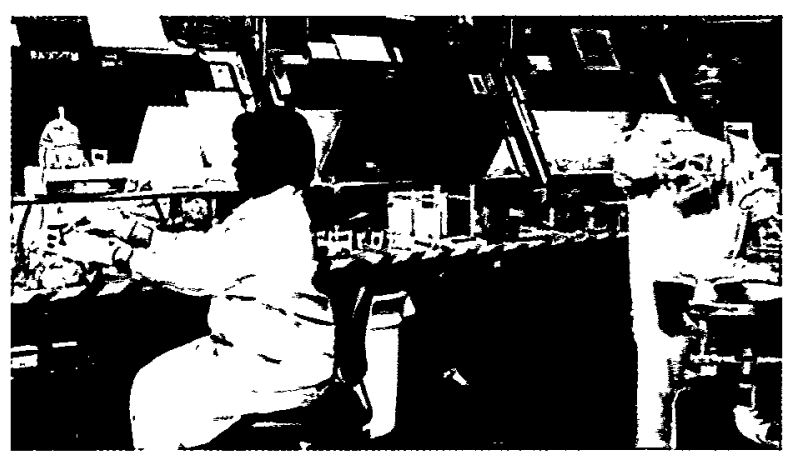

Figure 1. The Work Force by Gender and Age

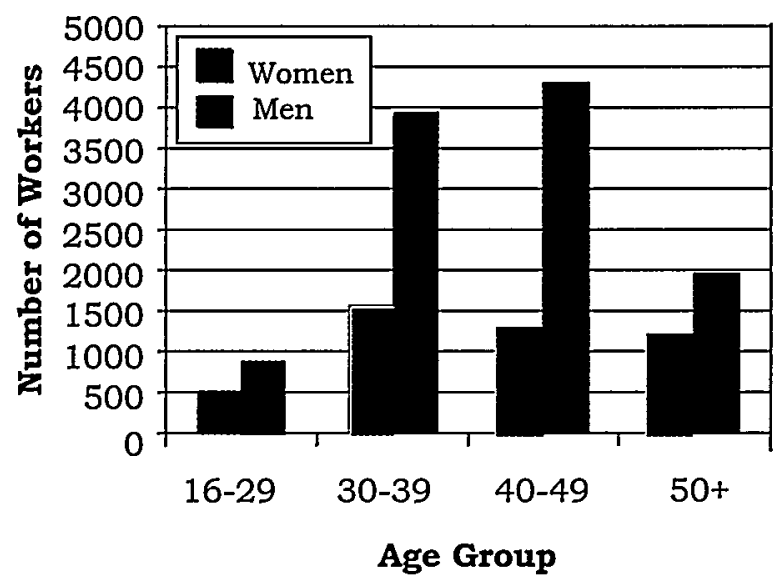

There were 10,955 men and 3,756 women in the work force. The average age of male SRS workers was 41 years and 39 years for females. The majority of the SRS workers was White (77 percent). African Americans comprised about 20 percent of the work force; Hispanics, Asians, Native Americans, and others made up the remaining 3 percent.
For this report, individual job titles reported by SRS were grouped together into job categories. The grouping was done because there were either too few workers or not enough health events among workers with a particular job title, which limited the types of analyses that could be conducted. Men and women were not distributed equally

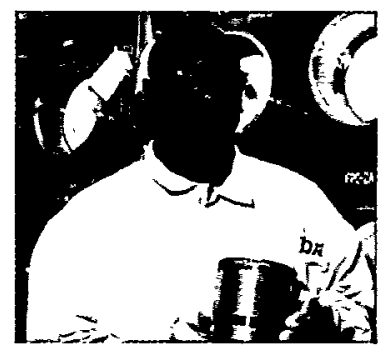
among the various job categories, as shown in Figure 2. Women were heavily represented in Office Management and Administration and in Technical Support positions. A larger percentage of men were engaged in Engineering, Scientific, and Health Care and Technical Support jobs. A more detailed distribution of the work force by gender, age, and job category is available in the supporting tables for this report at http:// www.eh.doe.gov/epi.

Figure 2. The Work Force by Job Category and Gender

\begin{tabular}{|lcc|}
\hline Job Category & Women & Men \\
\hline Office Management & 1,816 & 1,829 \\
\& Administration & $48 \%$ & $16 \%$ \\
\cline { 1 - 1 } Engineering, & & \\
Scientific \& Health & 333 & 2,781 \\
Care & $9 \%$ & $25 \%$ \\
\hline Technical Support & 1,299 & 4,583 \\
& $34 \%$ & $42 \%$ \\
Service & 17 & 77 \\
& $<1 \%$ & $1 \%$ \\
\hline Crafts \& & 160 & 1,204 \\
Manual Labor & $4 \%$ & $11 \%$ \\
\hline Nuclear Specialties & 122 & 408 \\
& $3 \%$ & $4 \%$ \\
\hline Power Operator & 9 & 73 \\
\hline
\end{tabular}




\section{Number and Length of Absences}

Epidemiologic surveillance examines absences of five or more consecutive workdays (also referred to as " 5 -day absences"). This threshold is based on DOE Order 440.1, which requires contractor management to notify Occupational Medicine when a worker has been absent for five or more consecutive work-

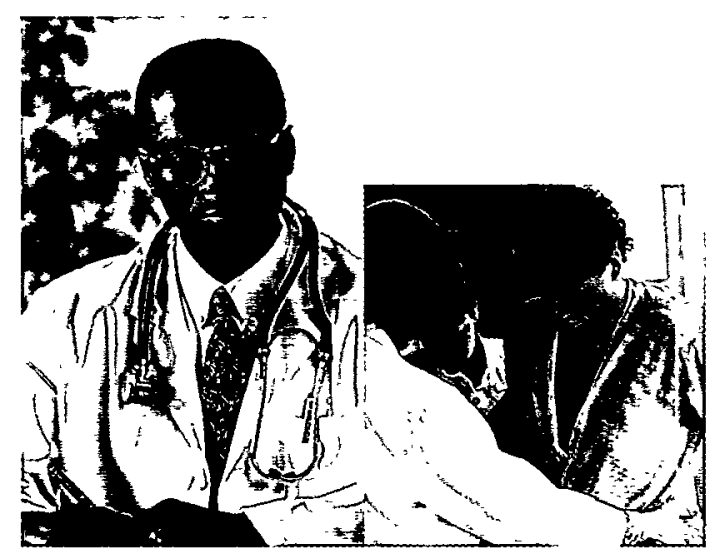

days or 40 consecutive work hours. If an absence overlaps a weekend, the weekend days are counted in the total duration of absence, but do not replace the 5 workday requirement. When an absence overlaps a weekend, the Friday and Monday surrounding that weekend are considered consecutive workdays. All work-related injuries and illnesses must be reported regardless of the length of absence. Non-occupational illnesses and injuries that involve absences of fewer than five days do not routinely require a medical clearance for return to work and are therefore excluded from these analyses.

One change from previous reports is the exclusion of certain absences that lasted at least five consecutive workdays but did not result from an illness or injury. These events included 107 women who reported 110 absences for maternity leave and 5 men and 6 women who reported 12 absences for elective surgical procedures not related to the treatment of an illness or injury.

Throughout this report, analyses take gender, age, and job category into account because the risk of illness and injury varies by these factors. This is done either by presenting the analyses in distinct age, gender, or job categories (stratification) or by statistical methods of adjustment.

Eight percent of the workers reported at least one absence in 1996, unchanged from the 1995 percentage. The 582 5-day absences among 3,756 women resulted in an absence rate of 15 per 100 workers; the rate among men was 7 per 100 workers $(779 / 10,955$, Figure 3$)$. For both men and women, the absence rate increased with age. For any given age,

Figure 3. Absence Rate by Gender and Age

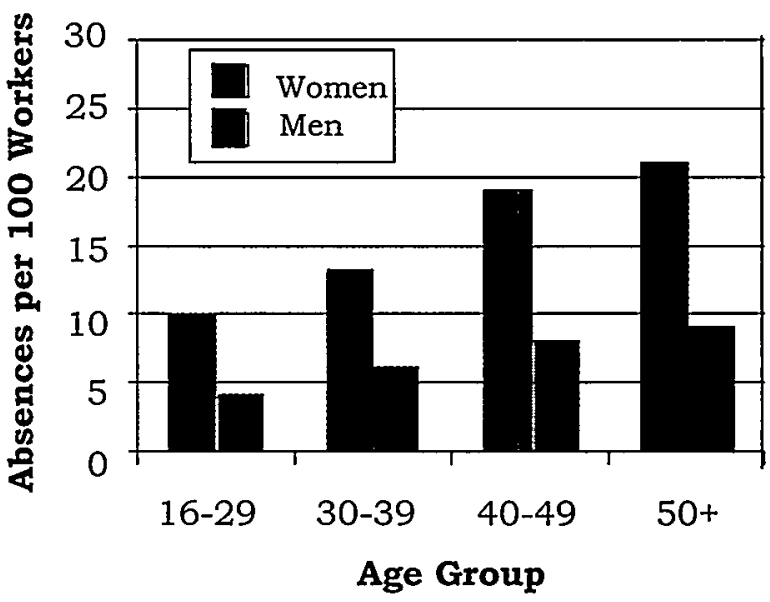

the absence rate among women was at least twice that of men. As shown in Figure 4, the average duration of absence was lowest for both men and women in the 16-29 age group. By comparison, the average duration of absence was higher among workers aged 30 and 
older but varied little among these older age groups. In all age groups, the average duration of absence was slightly higher among women than among men.

The dramatic decline in the number of 5-day absences seen from 1994 to 1995 did not continue into 1996. Including absences related to maternity leave, the number of absences reported in $1996(1,471)$ were comparable to the number reported in $1995(1,477)$.

Figure 4. Number of Days Absent by Gender and Age

\begin{tabular}{|c|c|c|c|c|}
\hline Gender & Age & $\begin{array}{c}\text { Number } \\
\text { of } \\
\text { Absences }\end{array}$ & $\begin{array}{c}\text { Number } \\
\text { of Days } \\
\text { Absent }\end{array}$ & $\begin{array}{c}\text { Average } \\
\text { Number } \\
\text { of Days } \\
\text { Absent }\end{array}$ \\
\hline $16-29$ & 48 & 909 & 19 \\
& $30-39$ & 198 & 5,285 & 27 \\
Women & $40-49$ & 246 & 6,428 & 26 \\
& $50+$ & 90 & 2,496 & 28 \\
& Total & 582 & 15,118 & 26 \\
& $16-29$ & 31 & 539 & 17 \\
& $30-39$ & 230 & 4,775 & 21 \\
Men & $40-49$ & 342 & 7,181 & 21 \\
& $50+$ & 176 & 4,168 & 24 \\
& Total & 779 & 16,663 & 21 \\
\hline
\end{tabular}

The rate of 5-day absences varied by job category for men and women (Figure 5). Women had higher rates of absence than did men across similar job categories. At 11 absences per 100 workers, men in the Nuclear Specialties had the highest rate $(43 / 408)$ among male workers, while those in the Service category had the lowest rate $(3 / 77)$ of 5 -day absences. Among women, Technical Support staff had the highest absence rate $(269 / 1,299)$, followed by Nuclear Specialists $(22 / 122)$.
As shown in Figure 6, there was no consistent pattern in average absence duration between men and women in various occupations. For the work force as a whole, the average duration of absence among women (26 days) was somewhat greater than that of men (21 days). Although Nuclear Specialties had the highest rate of 5-day absences among men, the average duration of their absences (about 18 days) was shorter than that of men in other job categories. Office Management and Administration workers had the longest average number of days absence $(24$ days) among men. Among women, Crafts and Manual Laborers had the shortest average absence (about 17 days). Service workers reported few absences but had the longest average duration of absence (80 days) among women. Additional details about the number and length of absences can be found in the supporting tables for this report.

\section{Figure 5. Absence Rate by Job Category and Gender}

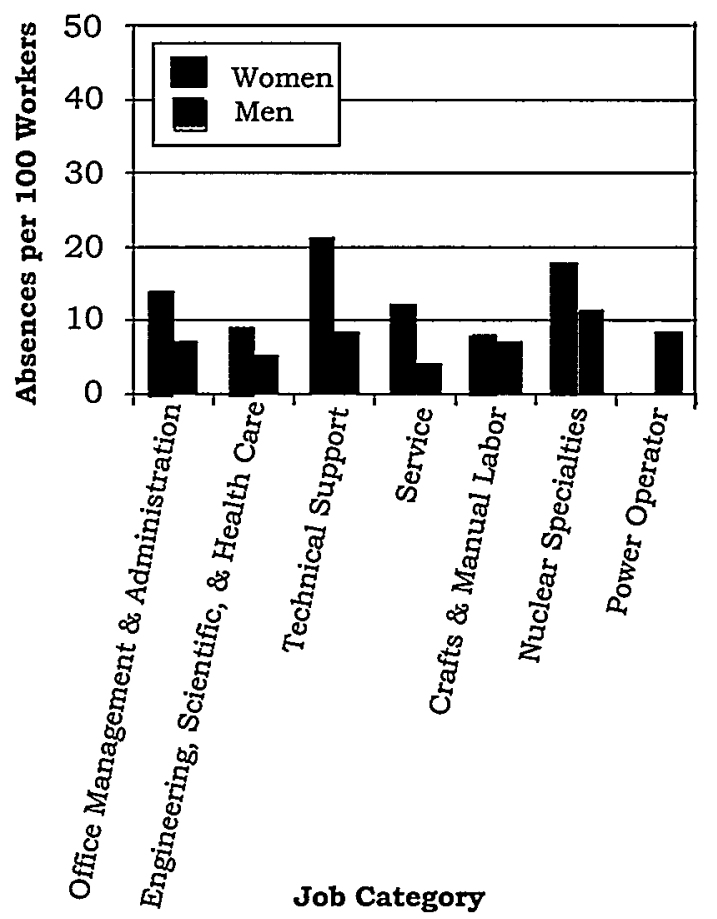


Figure 6. Average Duration of Absence by Job Category and Gender

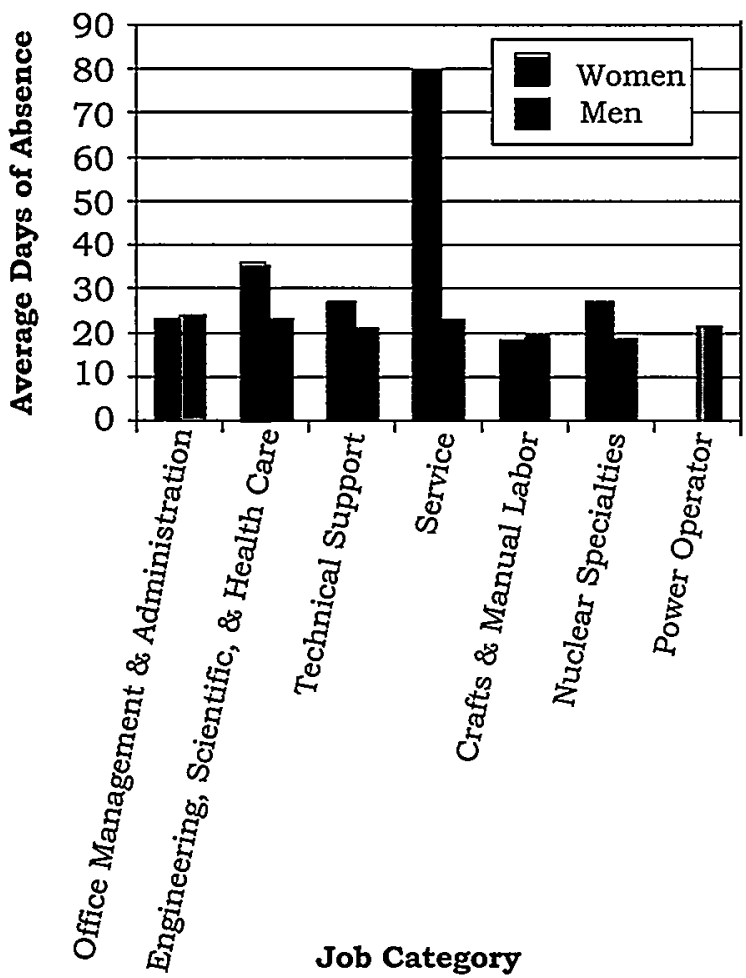

\section{Diagnostic Categories}

Epidemiologic surveillance monitors all illnesses and injuries among active workers because it is not always possible to determine what health effects are due to occupational exposures and what are due to other causes. Workers who required return-to-work clearances reported illness and injury diagnoses to the occupational medicine clinic. An absence due to illness or injury may involve more than one diagnosis, and epidemiologic surveillance includes all reported diagnoses. In addition, the OSHA 200 Log provides information on recorded occupational injuries and illnesses whether or not they involve absences.

This report organizes illness and injury categories based on a standard reference, the International Classification of Diseases, - $9^{\text {th }}$ Revision, Clinical Modification (ICD-9-CM). This reference is used to classify diagnoses for statistical purposes. You can find specific diagnoses in the Explanation of Diagnostic Categories.

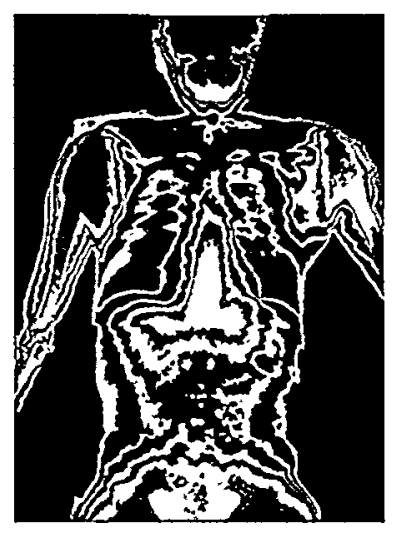

The number of reported diagnoses categorized according to the ICD-9-CM and number of lost calendar days are presented in Figure 7. Women reported 877 diagnoses and accrued 15,118 days of absence related to them. Men reported 1,035 diagnoses and 16,663 days of absence. The three leading diagnostic categories among women remained unchanged from 1995. Respiratory (19 percent), genitourinary (15 percent), and muscle and skeletal conditions (14 percent) accounted for 48 percent of all reported diagnoses among women. The majority of respiratory conditions was due to acute upper respiratory infections (46 percent), chronic obstructive pulmonary disease (primarily bronchitis) (23 percent), and flu and pneumonia (23 percent). Over 80 percent of the genitourinary conditions were related to disorders of the reproductive organs. Back pain and disk injuries made up 51 percent of muscle and skeletal conditions, followed by rheumatism ( 24 percent) and arthritis (18 percent).

Two of the three most frequently reported diagnoses were the same for men and women. Among men, 69 percent of all reported diagnoses were due to respiratory conditions (20 percent), 
muscle and skeletal conditions (16 percent), digestive conditions (11 percent), injuries (11 percent), and heart and circulatory conditions (11 percent). The respiratory diagnoses were primarily acute respiratory infections (38 percent) followed by pneumonia and flu (34 percent) and bronchitis (23 percent). A closer look at diagnoses affecting the muscles and skeleton showed that about 60 percent were back problems, and 36 percent involved arthritis or rheumatism. Forty-one percent of the digestive disorders were hernias. Sprains and strains comprised 25 percent of the injuries; fractures (25 percent) and dislocations ( 14 percent) were also common. We noted six allergic reactions and seven diagnoses related to complications of medical care reported among the 114 diagnoses categorized as injuries. Fiftynine percent of the circulatory diagnoses were hypertension (high blood pressure)

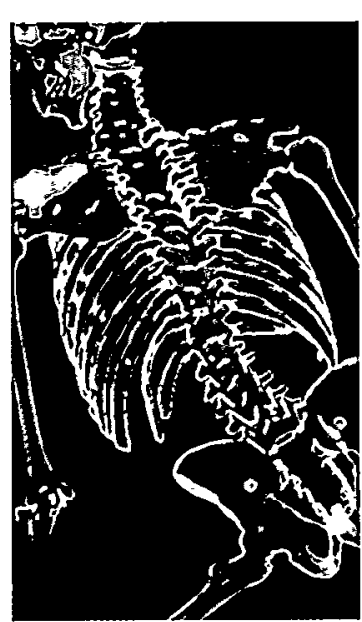
or ischemic heart disease (restricted blood flow to an artery in the heart).

\section{The above}

diagnoses varied by age. The most frequently reported diagnoses were more consistent among the various age groups of women than men. Conditions affecting the respiratory system ranked among the top three categories for men and women of all ages. Heart and circulatory conditions were primarily confined to men aged 50 and older. Muscle and skeletal diagnoses were common in men aged 30 to 49 and among women aged 30 and older. Genitourinary diagnoses were frequently reported by women younger than age 50 , but this diagnostic category was not common among men.

Figure 7. Number of Diagnoses and Lost Calendar Days by Diagnostic Category (Categorized by ICD-9-CM) and Gender

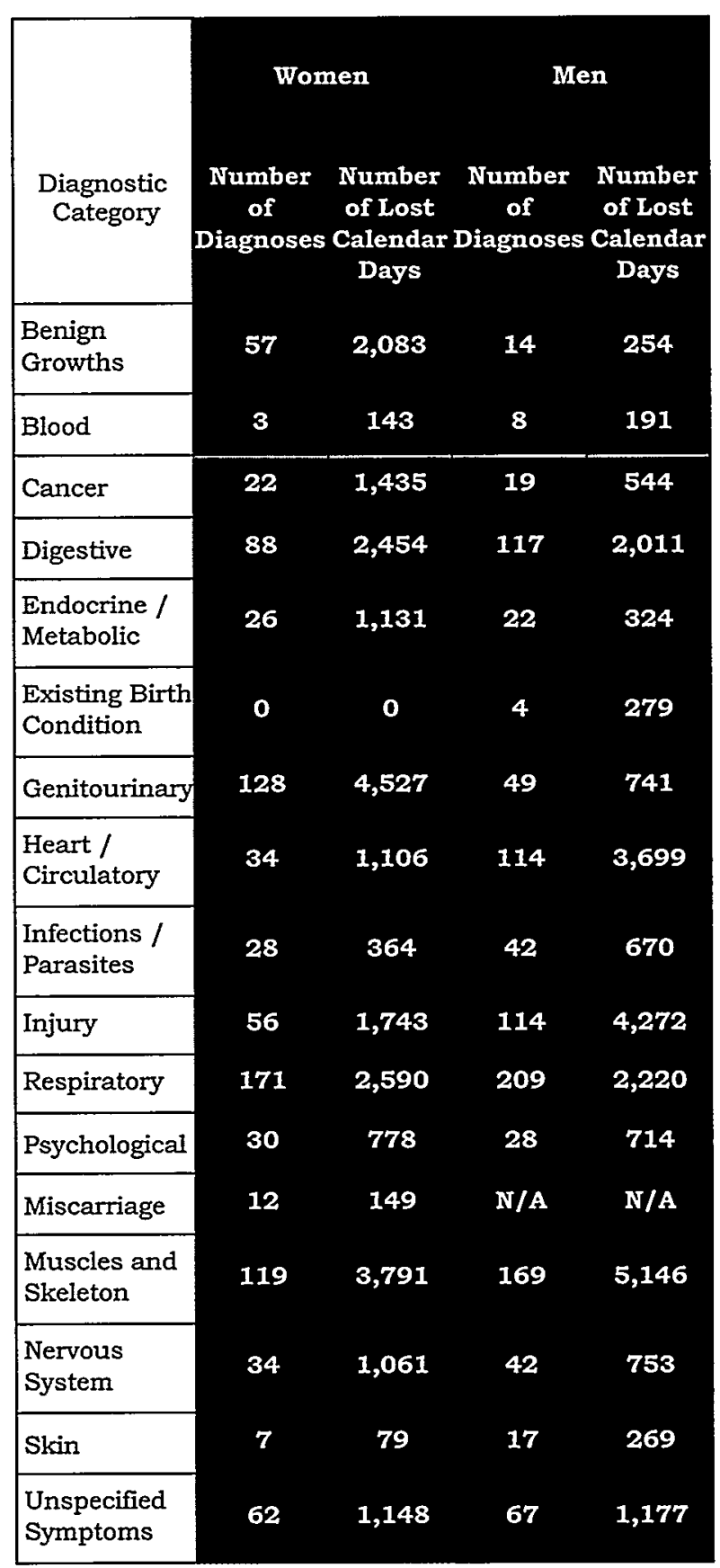

Note: Lost calendar days for each diagnosis are counted more than once if there are multiple diagnoses per absence. 
Injuries were among the more commonly noted diagnoses among men younger than age 40 , but among women injuries were reported frequently only in workers aged 50 or older.

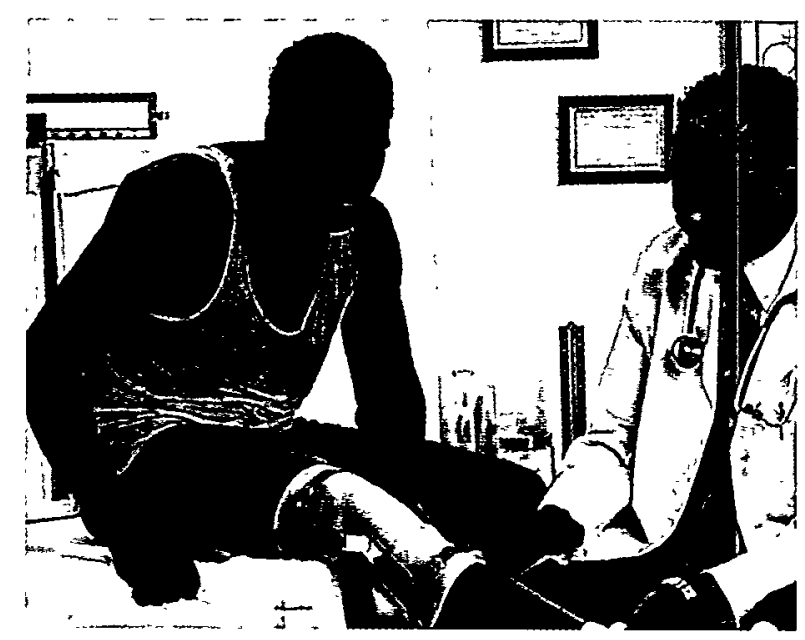

Figure 8 shows the frequency of reported diagnoses by job category for men and women. The types of diagnoses did not vary significantly by job category. Among men, muscle and skeletal conditions, injuries, and respiratory conditions appeared most often in nearly all job categories. Among women, conditions affecting the muscles and skeleton and respiratory diagnoses

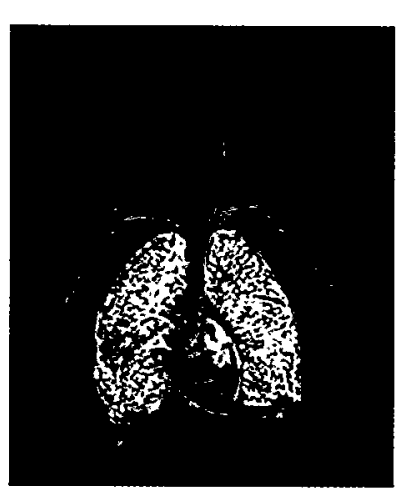

were common among most job categories. Among the Engineering, Scientific, and Health Care group, two women reported the nine cancer diagnoses. One woman had seven diagnoses

in three absences and the other had two diagnoses in one absence. The Supporting Tables contain more detailed information about diagnoses and absences by gender, age, and job category.
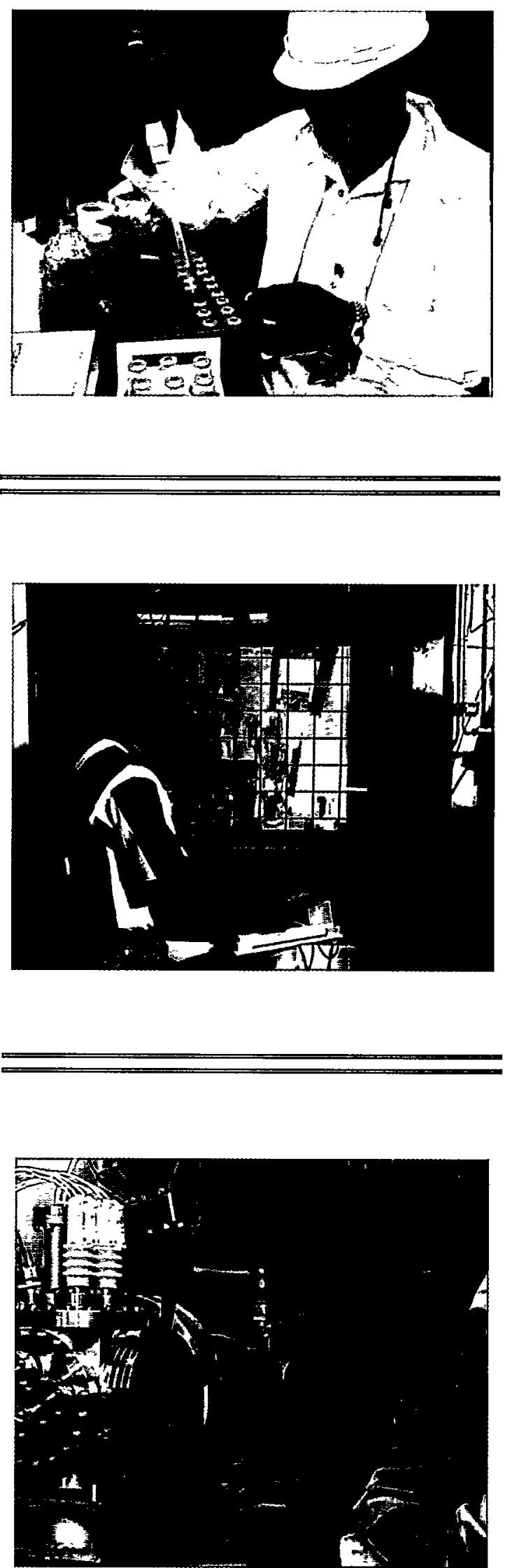
Figure 8. Most Frequently Reported Diagnoses by Job Category and Gender

\begin{tabular}{|c|c|c|}
\hline Job Category & Men & Women \\
\hline $\begin{array}{l}\text { Office } \\
\text { Management \& } \\
\text { Administration }\end{array}$ & $\begin{array}{l}\text { Muscles and } \\
\text { Skeleton (31) } \\
\text { Heart/ } \\
\text { Circulatory (29) } \\
\text { Injury (25) }\end{array}$ & $\begin{array}{l}\text { Respiratory (76) } \\
\text { Genitourinary } \\
\text { (53) } \\
\text { Muscles and } \\
\text { Skeleton (49) }\end{array}$ \\
\hline $\begin{array}{l}\text { Engineering, } \\
\text { Scientific, \& } \\
\text { Health Care }\end{array}$ & $\begin{array}{l}\text { Muscles and } \\
\text { Skeleton (33) } \\
\text { Respiratory (32) } \\
\text { Digestive (29) }\end{array}$ & $\begin{array}{l}\text { Digestive (10) } \\
\text { Cancer (9) } \\
\text { Muscles and } \\
\text { Skeleton (8) }\end{array}$ \\
\hline $\begin{array}{l}\text { Technical } \\
\text { Support }\end{array}$ & $\begin{array}{l}\text { Respiratory (110) } \\
\text { Muscles and } \\
\text { Slzeleton (69) } \\
\text { Injury (59) }\end{array}$ & $\begin{array}{l}\text { Respiratory (80) } \\
\text { Genitourinary } \\
\text { (69) } \\
\text { Muscles and } \\
\text { Skeleton (54) }\end{array}$ \\
\hline Service & $\begin{array}{l}\text { Respiratory (3) } \\
\text { Muscles and } \\
\text { Skeleton (1) } \\
\text { Unspecified } \\
\text { Symptoms (1) }\end{array}$ & $\begin{array}{l}\text { Heart/ } \\
\text { Circulatory (2) } \\
\text { Unspecified } \\
\text { Symptoms (2) } \\
\text { Genitourinary } \\
\text { (1) }\end{array}$ \\
\hline $\begin{array}{l}\text { Crafts \& } \\
\text { Manual Labor }\end{array}$ & $\begin{array}{l}\text { Muscles and } \\
\text { Skeleton (28) } \\
\text { Respiratory (15) } \\
\text { Digestive (11) } \\
\text { Injury (11) }\end{array}$ & $\begin{array}{l}\text { Respiratory (4) } \\
\text { Injury (2) } \\
\text { Miscarriage (2) } \\
\text { Muscles and } \\
\text { Skeleton (2) } \\
\text { Unspecified } \\
\text { Symptoms (2) }\end{array}$ \\
\hline $\begin{array}{l}\text { Nuclear } \\
\text { Specialties }\end{array}$ & $\begin{array}{l}\text { Respiratory (24) } \\
\text { Heart/ } \\
\text { Circulatory (8) } \\
\text { Injury (8) } \\
\text { Muscles and } \\
\text { Skeleton (6) }\end{array}$ & $\begin{array}{l}\text { Respiratory (6) } \\
\text { Muscles and } \\
\text { Skeleton (6) } \\
\text { Unspecified } \\
\text { Symptoms (4) }\end{array}$ \\
\hline $\begin{array}{l}\text { Power } \\
\text { Operator }\end{array}$ & $\begin{array}{l}\text { Unspecified } \\
\text { Symptoms (4) } \\
\text { Respiratory (2) }\end{array}$ & None \\
\hline
\end{tabular}

Note: Numbers in parentheses are number of diagnoses reported.

\section{Rates of Disease Occurrence}

A Word about Rates: The previous section considered the number of absences and diagnoses among various worker groups. For example, Figure 7 shows that men reported 169 and women reported 119 diagnoses involving muscle and skeletal conditions during 1996. Men therefore reported more muscle and skeleton diagnoses than women reported. As there were almost three times more men than women at Savannah River, it seems reasonable to expect more muscle and skeletal conditions among men than women. Does this mean that men were at greater risk of muscle and skeletal conditions compared with women in 1996? To correctly answer the question, the total number of men and women in the work force must be considered. A more accurate way to compare risk among men and women is to calculate the rate of muscle and skeletal conditions for each gender. Rates are calculated by dividing the number of muscle and skeletal diagnoses in a given gender by the total number of employees of that gender. Multiply this number by 1,000 to get the diagnosis rate per 1,000 workers.

For example:

169 muscle and skeletal conditions

$\div 10,955$ men $=.015 \times 1,000$

$=15$ muscle and skeletal conditions per 1,000 men

119 muscle and skeletal conditions $\div 3,756$ women $=.032 \times 1,000$

$=32$ muscle and skeletal conditions per 1,000 women

Comparing these rates now correctly suggests that reported absences due to muscle and skeletal conditions among women were twice the rates for men. They are called crude rates because they do not account for possible differences between men and women in factors such as age that might affect the individual's risk of having a muscle and skeletal disorder. Because age is so strongly related to the risk of disease and injury, epidemiologists almost always take age into account when comparing groups. This is done by using age-specific categories or by methods of statistical adjustment. 
The diagnosis rate (also called the illness and injury rate) is the number of occurrences of a given disease or health condition observed over the course of a year per 1,000 workers at risk of getting that condition (see shaded box). One health condition, arthritis for example, may result in several 5-day absences over a year. Conversely, one 5-day absence may be associated with multiple diagnoses (e.g., the flu and a sprained wrist) recorded on one return-to-work form.

In the following analyses the four age groups were collapsed into two: workers less than 50 years of age and those aged 50 or older (see Figure 9). In addition, the seven occupational groups were combined into five larger groups. These groups were collapsed to ensure that the number of diagnoses in each group was large enough to analyze. Five groups of diagnoses of particular interest to workers are presented: all illnesses and injuries combined, cancer, heart/ circulatory system, respiratory system, and injury. Additional information about other disease groups can be found in the Supporting Tables.

Figure 9. Illness and Injury Rates by Job Category, Gender, and Age

\begin{tabular}{|c|c|c|c|c|}
\hline $\begin{array}{l}\text { Diagnostic } \\
\text { Category }\end{array}$ & \multicolumn{4}{|c|}{ Rate per 1,000} \\
\hline \multirow[t]{11}{*}{$\begin{array}{l}\text { All Illnesses } \\
\& \text { Injuries } \\
\text { Combined }\end{array}$} & Job Category & Age & Men & Women \\
\hline & Office Management & $<50$ & 91 & 186 \\
\hline & \& Administration & $50+$ & 120 & 271 \\
\hline & Engineering, & $<50$ & 56 & \\
\hline & Health Care & $50+$ & 105 & 552 \\
\hline & & $<50$ & 100 & 317 \\
\hline & tecrincal suppor & $50+$ & 145 & 365 \\
\hline & Service / Crafts \& & $<50$ & 1,246 & 813 \\
\hline & Manual Labor & $50+$ & 2,500 & 6,000 \\
\hline & Nuclear & $<50$ & 173 & 267 \\
\hline & Power Operator & $50+$ & 218 & 667 \\
\hline
\end{tabular}

\begin{tabular}{|c|c|c|c|c|}
\hline $\begin{array}{l}\text { Diagnostic } \\
\text { Category }\end{array}$ & \multicolumn{4}{|c|}{ Rate per 1,000} \\
\hline \multirow[t]{11}{*}{ Cancer } & Job Category & Age & Men & Women \\
\hline & \multirow{2}{*}{$\begin{array}{l}\text { Office Management } \\
\text { \& Administration }\end{array}$} & $<50$ & 4 & $\mathbf{3}$ \\
\hline & & $50+$ & 2 & 4 \\
\hline & \multirow{2}{*}{$\begin{array}{l}\text { Engineering, } \\
\text { Scientific, \& } \\
\text { Health Care }\end{array}$} & $<50$ & 1 & 23 \\
\hline & & $50+$ & 6 & 69 \\
\hline & \multirow{2}{*}{ Technical Support } & $<50$ & 1 & 4 \\
\hline & & $50+$ & 0 & 19 \\
\hline & \multirow{2}{*}{$\begin{array}{l}\text { Service / Crafts \& } \\
\text { Manual Labor }\end{array}$} & $<50$ & 0 & 0 \\
\hline & & $50+$ & 83 & 0 \\
\hline & \multirow{2}{*}{$\begin{array}{l}\text { Nuclear Specialties/ } \\
\text { Power Operator }\end{array}$} & $<50$ & 0 & 0 \\
\hline & & $50+$ & 13 & 0 \\
\hline
\end{tabular}

\begin{tabular}{|c|c|c|c|c|}
\hline $\begin{array}{l}\text { Diagnostic } \\
\text { Category }\end{array}$ & \multicolumn{4}{|c|}{ Rate per 1,000} \\
\hline $\begin{array}{l}\text { Heart / } \\
\text { Circulatory }\end{array}$ & Job Category & Age & Men & Women \\
\hline & Office Management & $<50$ & 10 & $\mathbf{5}$ \\
\hline & \& Administration & $50+$ & 33 & 4 \\
\hline & Engineering, & $<50$ & 3 & 0 \\
\hline & Health Care & $50+$ & 27 & 34 \\
\hline & Torhningl Sinnont & $<50$ & 8 & 16 \\
\hline & Technical support & $50+$ & 25 & 0 \\
\hline & Service / Crafts 8 & $<50$ & 46 & $\mathbf{0}$ \\
\hline & Manual Labor & $50+$ & 417 & 2,000 \\
\hline & es/ & $<50$ & 18 & 26 \\
\hline & Por & $50+$ & 38 & 0 \\
\hline
\end{tabular}

\begin{tabular}{|c|c|c|c|c|}
\hline $\begin{array}{l}\text { Diagnostic } \\
\text { Category }\end{array}$ & \multicolumn{4}{|c|}{ Rate per 1,000} \\
\hline Respi & Job Category & Age & Men & Women \\
\hline \multirow{10}{*}{ 要 } & \multirow{2}{*}{$\begin{array}{l}\text { Office Management } \\
\& \& \text { Administration }\end{array}$} & $<50$ & 12 & 39 \\
\hline & & $50+$ & 13 & 56 \\
\hline & \multirow{2}{*}{$\begin{array}{l}\text { Engineering, } \\
\text { Scientific, \& } \\
\text { Health Care }\end{array}$} & $<50$ & 10 & 13 \\
\hline & & $50+$ & 15 & 34 \\
\hline & \multirow{2}{*}{ Technical Support } & $<50$ & 22 & 54 \\
\hline & & $50+$ & 37 & 144 \\
\hline & \multirow{2}{*}{$\begin{array}{l}\text { Service / Crafts } 8 \\
\text { Manual Labor }\end{array}$} & $<50$ & 185 & 250 \\
\hline & & $50+$ & 500 & 0 \\
\hline & \multirow{2}{*}{$\begin{array}{l}\text { Nuclear Specialties/ } \\
\text { Power Operator }\end{array}$} & $<50$ & 67 & 34 \\
\hline & & $50+$ & 51 & 333 \\
\hline
\end{tabular}

\begin{tabular}{|c|c|c|c|c|}
\hline $\begin{array}{l}\text { Diagnostic } \\
\text { Category }\end{array}$ & \multicolumn{4}{|c|}{ Rate per 1,000} \\
\hline Injury & Job Category & Age & \multirow{2}{*}{$\begin{array}{c}\text { Men } \\
13\end{array}$} & \multirow{2}{*}{$\begin{array}{l}\text { Women } \\
12\end{array}$} \\
\hline & \multirow{2}{*}{$\begin{array}{l}\text { Office Management } \\
\text { \& Administration }\end{array}$} & $<50$ & & \\
\hline & & $50+$ & 16 & 41 \\
\hline & \multirow{2}{*}{$\begin{array}{l}\text { Engineering, } \\
\text { Scientific, \& } \\
\text { Health Care }\end{array}$} & $<50$ & 3 & 3 \\
\hline & & $50 \div$ & 6 & 69 \\
\hline & \multirow{2}{*}{ Technical Support } & $<50$ & 13 & 17 \\
\hline & & $\overline{50+}$ & 10 & 0 \\
\hline & \multirow{2}{*}{$\begin{array}{l}\text { Service / Crafts \& } \\
\text { Manual Labor }\end{array}$} & $<50$ & 138 & 63 \\
\hline & & $50+$ & 167 & 1,000 \\
\hline & \multirow{2}{*}{$\begin{array}{l}\text { Nuclear Specialties/ } \\
\text { Power Operator }\end{array}$} & $<50$ & 21 & 9 \\
\hline & & $50+$ & 13 & 0 \\
\hline
\end{tabular}


In general, the rate of all illnesses and injuries combined was greater among workers aged 50 and older (Figure 9). The highest rates were observed among workers classified as Service/ Crafts and Manual Labor. With one exception, the rates for female employees were higher than those of men within a particular job category.

Cancer rates in this report are based on reported 5-day absences during the year. A worker may experience several periods of absence from one cancer diagnosis due to medical complications or recurrent treatment. Each reported absence results in a report of a cancer diagnosis. However, it does not imply that this is necessarily a new cancer. The cancer rates in this report are not comparable to the incidence rates frequently published in many articles on cancer with which you may be familiar. Incident cancer rates are based on the number of new cancer cases diagnosed within a given time, usually a year.

The likelihood that an individual in the U.S. will develop cancer increases with age. Cancer rates at SRS were generally higher among workers aged 50 and over than among younger workers. Forty-one diagnoses related to cancer were reported, 19 diagnoses among 17 men and 22 diagnoses among 13 women. Three of the workers reporting cancer in 1996 had reported cancer previously, two in 1995 and one in

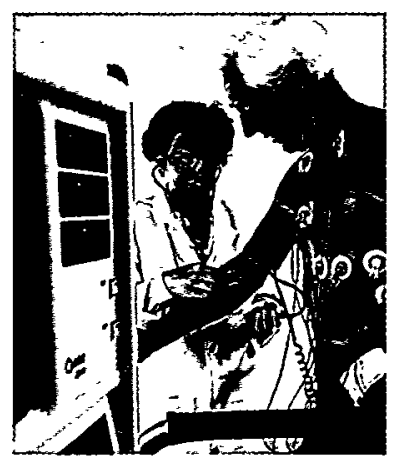
1994 and 1995. In each case, these three workers reported a different site of cancer in 1966 than they had reported in previous years. For two of these workers, the cancer appears to have spread from an adjacent organ. The third worker reported Hodgkin's disease in 1994, 1995, and 1996 plus cervical cancer in 1996. We observed no evidence of an excess of any particular type of cancer, nor any evidence that a particular occupational group had an excess of reported cancer.

Men aged 50 and older had the highest rates of heart and circulatory problems. Fifty-three of the 114 absences among men occurred in workers aged 50 and older, and about two-thirds (35/53) of these diagnoses involved ischemic heart disease (restricted blood flow through an artery). Among men, the Service/Crafts and Manual Laborers aged 50 and older had the highest rate of heart and circulatory diagnoses. Women reported 34 heart/ circulatory diagnoses,

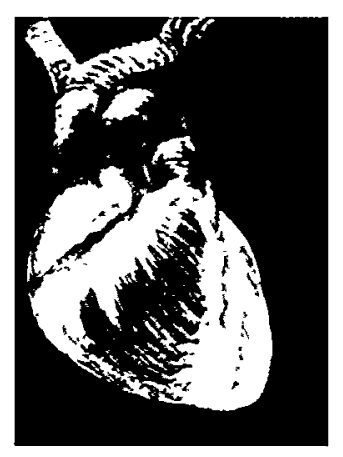
of which 4 were reported by women aged 50+. Thirteen of the 34 diagnoses involved hypertension and two ischemic heart diseases. The apparently startling rate of 2,000 events per 1,000 workers aged 50 and older noted in the Service/ Crafts and Manual Labor group actually reflected only one woman's absence for hypertension and acute cerebrovascular disease.

Women generally had higher rates of respiratory disease than men, and both male and female workers aged 50 and older had higher rates than younger workers. Service/Crafts and Manual Labor workers had the highest rates of respiratory diagnoses among men compared with other job categories. Technical Support and Nuclear Specialties / 
Power Operator workers were also more likely to report a respiratory condition than were other workers.

The injuries in this analysis included

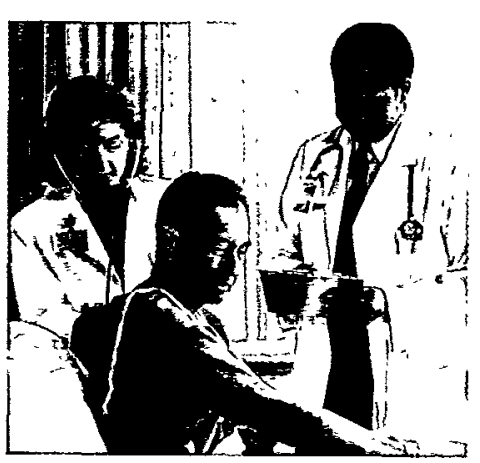
both occupational and nonoccupational injuries. We found no consistent pattern of injury diagnoses with age, although

Savannah River workers aged 50 and older appeared to be at slightly higher risk than those under 50. The occurrence of injuries was not related to gender in a consistent manner.

Occupationally, Technical Support workers were 3 times and Crafts and Manual Labor workers 4 times more likely to report a back sprain or strain than were other groups. We compared the risk of illness and injury among workers classified in one job category with workers in the remaining job categories. Technical Support workers were at 30 percent greater risk compared with other groups, but in general we found no remarkable differences in risk for illness or injury based on job category.

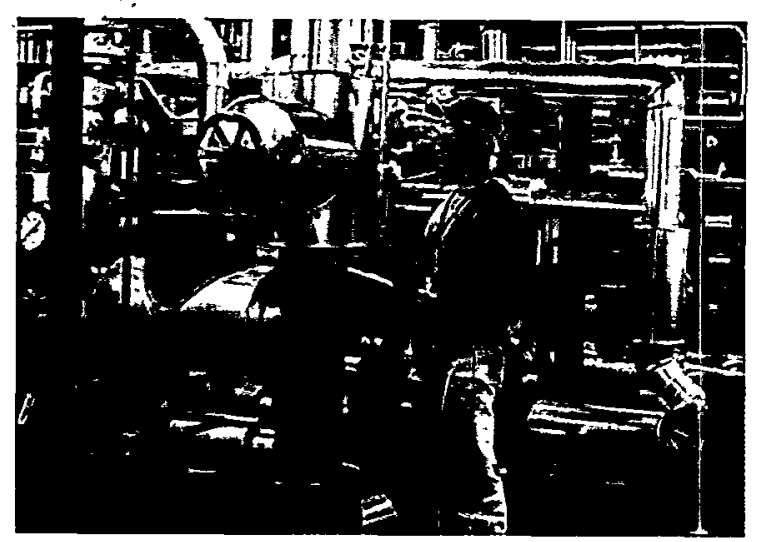

\section{Time Trends}

\section{Why Are Rates Age-Adjusted?}

The injury and illness rates in this section of the report are ageadjusted. Differences in the age distribution of different groups of workers are taken into consideration in the analyses and one rate is calculated for an entire group. This allows us to make comparisons between groups with different age distributions. Age-adjusted rates are calculated using the age distribution of the 1970 U.S. population as a reference.

The availability of three years of epidemiologic surveillance data for Savannah River workers permitted us to analyze illness and injury trends over time in the work force. It is important to note that the age-adjusted rates for the years 1994 and 1995 presented in this report differ from the 1994 and 1995 Annual Epidemiologic Surveillance Reports due to the exclusion of diagnoses resulting from maternity leave. Age-adjusted rates for all illness and injury categories combined are presented in Figure 10.

The age-adjusted rates for all illness and injury categories combined decreased among men and women in most job categories over the past three years. The only exception was a rebound to an overall diagnosis rate higher than that observed in 1994 among women Service workers. Most of this decline occurred between 1994 and 1995. 
Figure 10. Age-Adjusted Rates for All Diagnoses Combined Among Women and Men by Job Category from 1994 to 1996
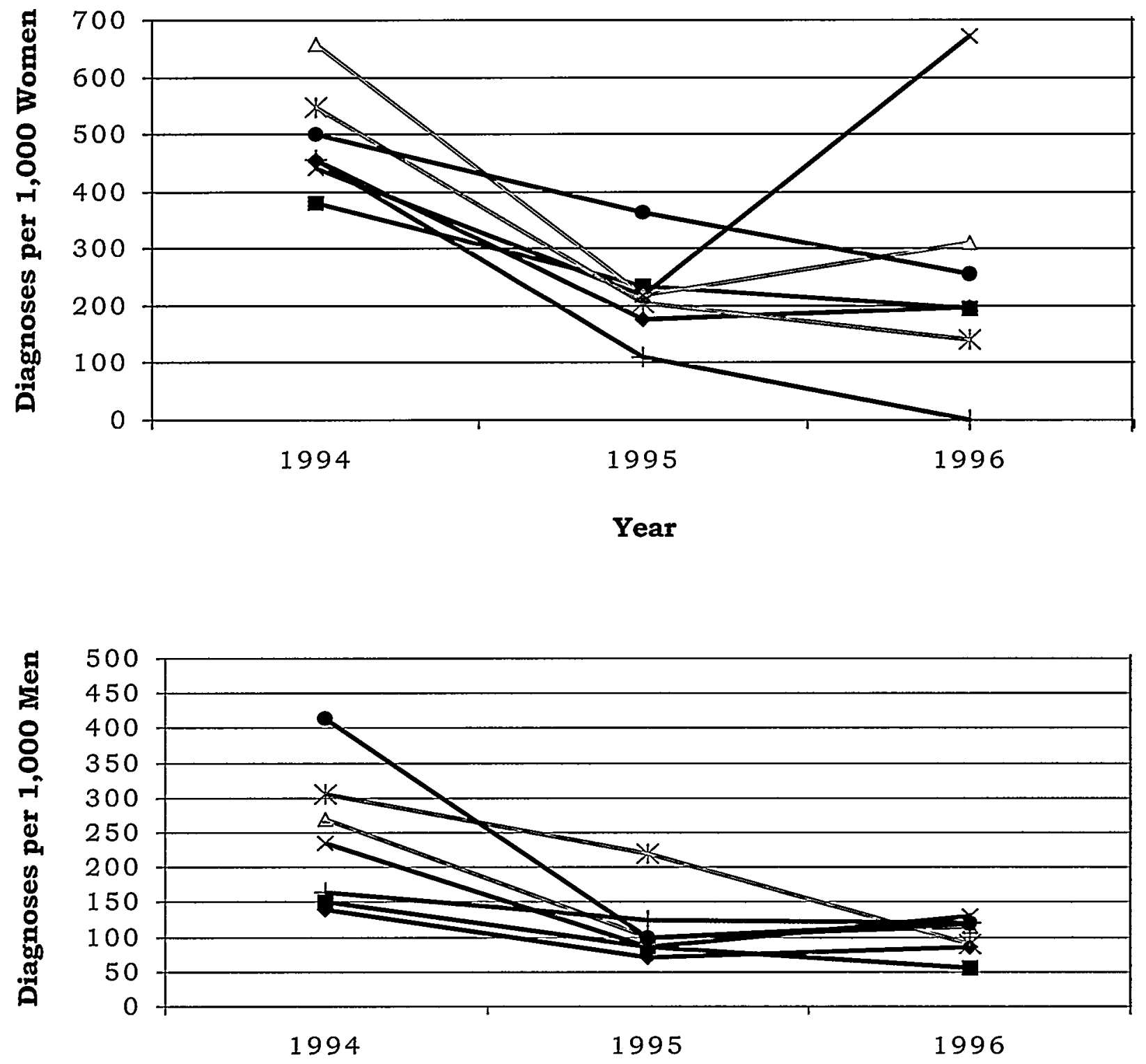

Year

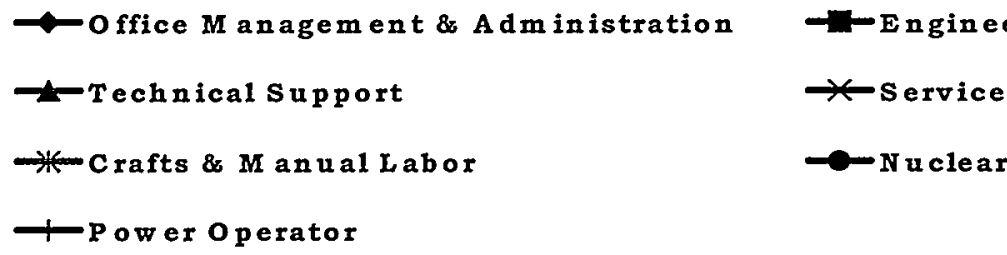


A number of policy changes implemented in 1994 may explain the decline. One change increased the number of days from two to five before a worker was required to seek medical attention for an absence. The other was the increased

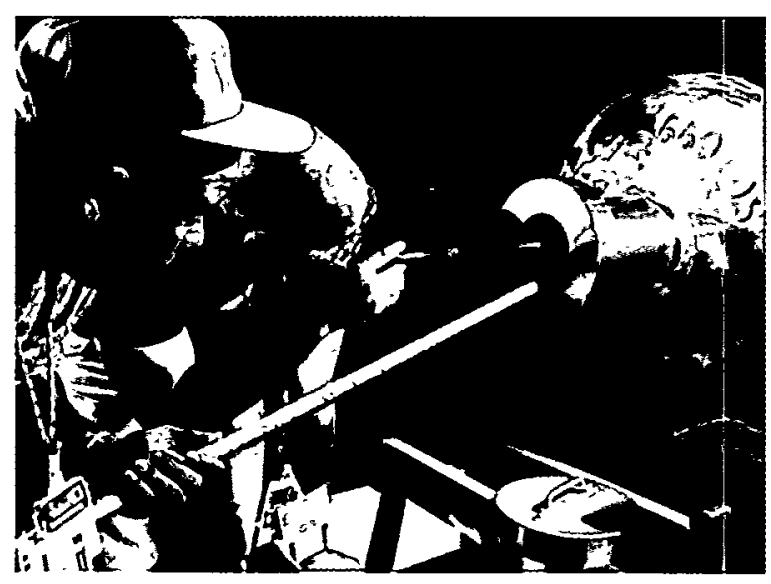

use of alternate work schedules by SRS workers. Four-day, 10-hour shifts were introduced in November 1994 and nineday, 80-hour schedules in April 1995.

Workers still using the five-day, 40-hour work schedule are a distinct minority. Since the Worker Protection Order indicates that a return-to-work clearance for a nonoccupational absence is required after five consecutive workdays or 40 hours or more, the guidance is not clear about someone on an alternate work schedule. The requirement for reporting an absence may be a matter of interpretation, thus affecting the reporting of absences.

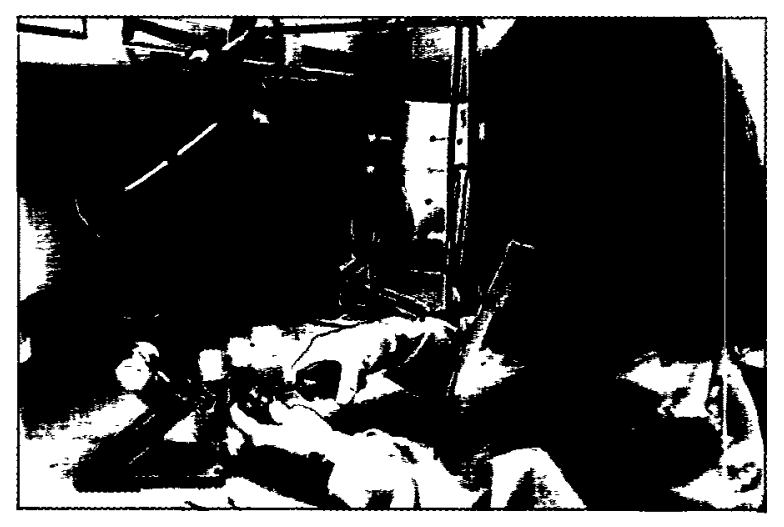

Age-adjusted rates for selected illness and injury categories are presented in Figure 11. The decline in the diagnostic rate for all injuries and illnesses combined was more dramatic among women than men. We noted a decline in the respiratory diagnosis rate among women and a small decrease in injuries, while rates of heart and circulatory disease and cancer remained low. Among men, respiratory conditions declined slightly. Diagnoses rates for cancer, heart and circulatory conditions, and injuries remained low.

Figure 11. Age-Adjusted Rates for Selected Diagnostic Categories for Men and Women from 1994 to 1996
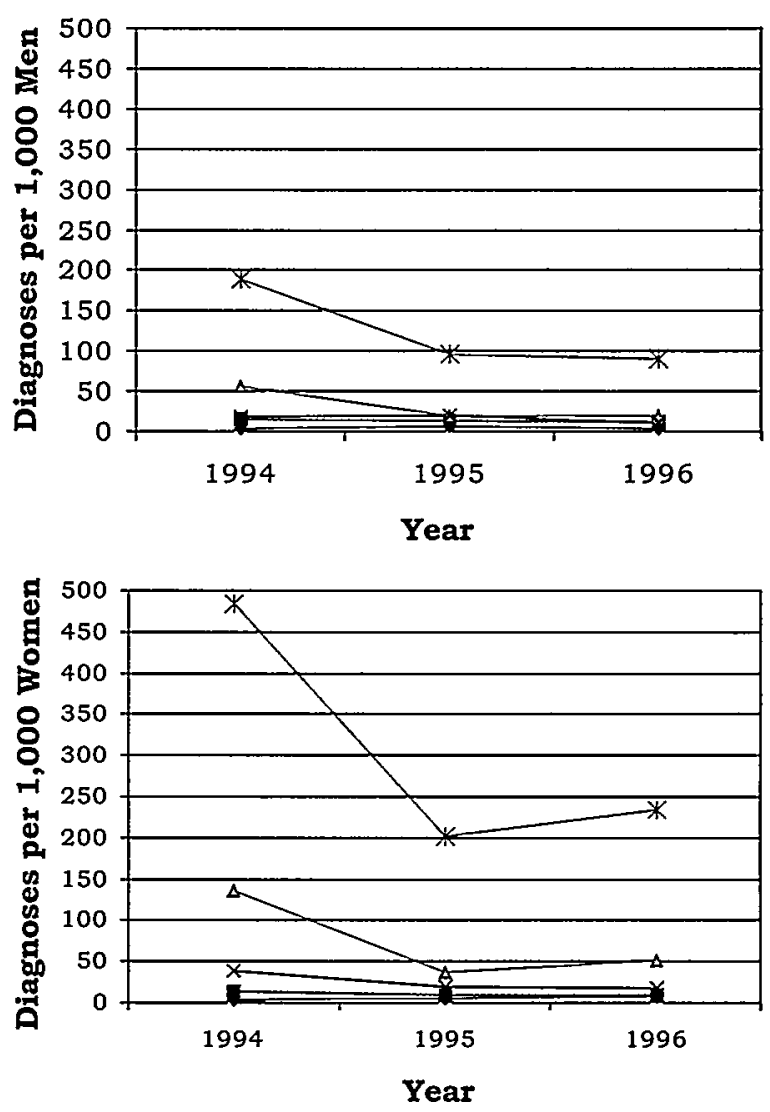

\begin{tabular}{ll}
$\rightarrow-$ Cancer & - Heart/Circulatory \\
$-\triangle$-Respiratory & $*$ Injury \\
*-All Diagnoses & \\
\hline
\end{tabular}




\section{Sentinel Health Events for Occupations}

A sentinel health event for occupation (SHEO) is a disease, injury, or death, which is likely to be occupationally related. Its occurrence may serve as a warning signal that materials substitution, engineering controls, personal protection, or medical care may be required to reduce the risk of illness or injury among the work force. Sixty-four

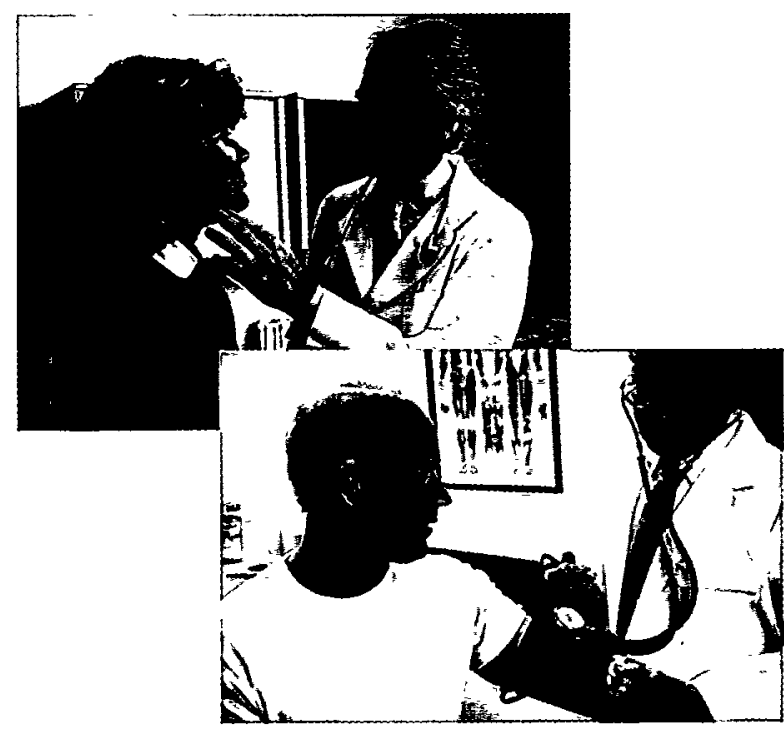

medical conditions associated with workplace exposures from studies of many different industries have been identified as occupational sentinel health events (see Supporting Tables).

Although sentinel health events may indicate an occupational exposure, many may result from non-occupational exposures. Due to this uncertainty, sentinel health events are assessed in two categories:

Definite Sentinel Health Events: Diseases that are unlikely to occur in the absence of an occupational exposure. Asbestosis, a lung condition resulting from exposure to asbestos, is an example.

Possible Sentinel Health Events: Conditions such as lung cancer or carpal tunnel syndrome that may or may not be related to occupation. Detailed occupational and non-occupational information is required to determine the work-relatedness of the illness. For example, lung cancer may result from asbestos exposure or from cigarette smoking. Carpal tunnel syndrome may result from a job requiring typing or from a hobby such as playing the piano.

No definite sentinel health events were reported in 1996, and 20 of the 1,361 health events (1 percent) were identified as possible sentinel health events (Figure 12). Fifteen of these events involved carpal tunnel syndrome diagnosed among 15 workers (5 women and 10 men) and resulted in 339 days of absence, 67 percent of the total number of days absent from sentinel health events. Carpal tunnel syndrome cases were reported in all occupational groups except the Service and Power Operator groups. Thirteen ( 87 percent) of the workers reporting this diagnosis were aged 40 or older.

Figure 12. Characteristics of SHEOs by Gender

\begin{tabular}{|c|cccc|}
\hline & \multicolumn{2}{|c|}{$\begin{array}{c}\text { Total Number } \\
\text { of SHEO } \\
\text { Diagnoses }\end{array}$} & \multicolumn{2}{c|}{$\begin{array}{c}\text { Total Number } \\
\text { of Days Absent }\end{array}$} \\
\cline { 1 - 5 } Men & Women & Men & Women \\
\cline { 1 - 4 } Definite & 0 & 0 & 0 & 0 \\
\cline { 1 - 5 } Possible & 13 & 7 & 293 & 216 \\
\cline { 1 - 5 } Total & 13 & 7 & 293 & 216 \\
\hline
\end{tabular}




\section{Disabilities Among Active Workers}

Nine women and 26 men were placed on long-term disability during 1996. Over one-third of the disabilities involved muscle and skeletal disorders: 9 back, 2 joint, and 2 connective tissue. The reasons for the remaining disabilities included 4 cancers, 7 occurrences of heart disease, 4 nervous system disorders, 3 psychological disorders, 2 existing birth conditions, and 1 each for digestive and blood disorders.

Workers aged 40 to 49 made up 38 percent of the work force, but they accounted for 66 percent of the disabled workers. In 1995, workers in this age group (33 percent of the work force) accounted for 37 percent of the disabilities. SRS did not report disability data in 1994. The disabled workers were excluded from other analyses in this report because they were not actively working.

\section{Deaths Among Active Workers}

During 1996, 22 deaths occurred among active workers: 20 men and 2 women. Four deaths were due to cancer and 4 others were attributed to heart disease. Six deaths resulted from injuries: 1 motor vehicle accident, 1 case of third-degree burns, 3 gunshot wounds, and 1 carbon monoxide poisoning. Two deaths were caused by disorders of the respiratory system and the causes of 6 deaths were unknown. Eight of the deaths among men and 1 of the deaths among women occurred in workers less than 40 years of age. Half of the deaths were among Technical Support workers.

\section{OSHA-Recordable Events}

The Occupational Safety and Health Administration (OSHA) requires that employers maintain a record of occupational injuries and illnesses occurring among employees and to make that information available to OSHA upon request. Employers maintain the information from these OSHA-recordable events in the OSHA $200 \mathrm{Log}$. OSHArecordable events differ from absences captured through return-to-work clearances in at least two important respects: 1) they do not necessarily result in days lost from work, and 2) they are usually accompanied by a specific determination that they are work-related.

Figure 13 shows the distribution of OSHA events by age and gender. The 171 workers with at least one OSHA event in 1996 represented a 54 percent increase compared with the number of workers in 1995. In 1995, men reported approximately two and a half times as many OSHA events as women; in 1996, men had three times more events than women.

Figure 13. OSHA-Recordable Events by Gender and Age

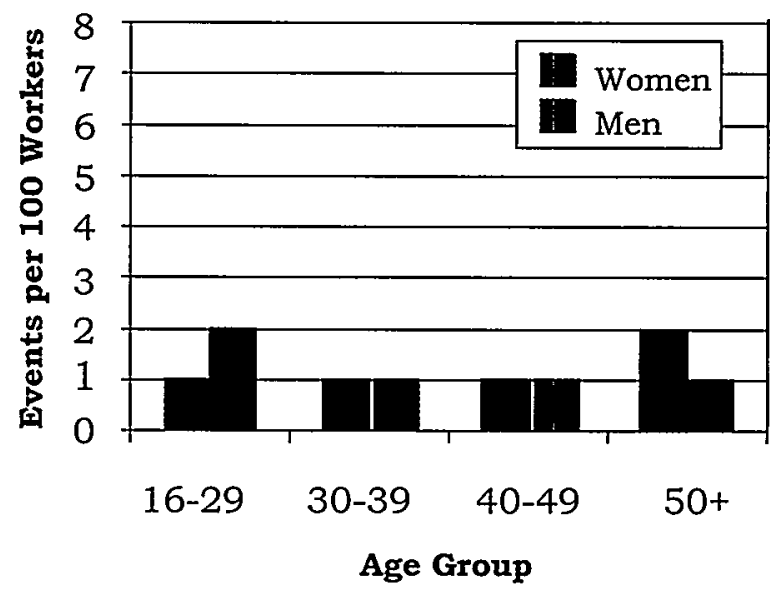


Figure 14. OSHA-Recordable Events by Job Category and Gender

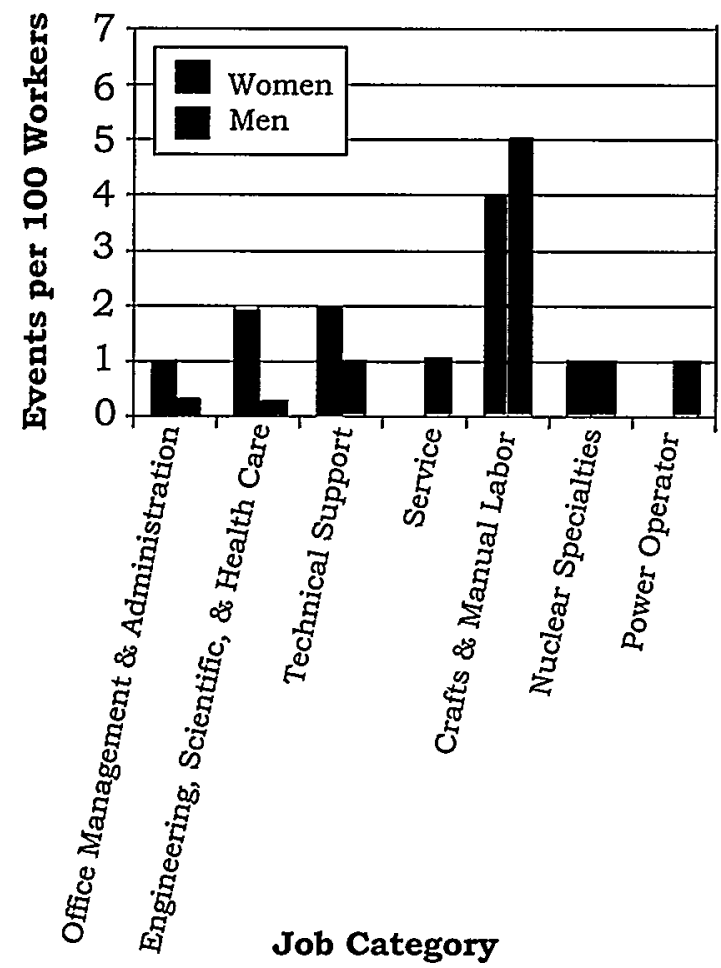

The rate of OSHA-recordable events was about the same for women and men in 1996. The occurrence of OSHArecordable injuries did not appear related to age.

The rates of OSHA-recordable events by job category and gender are shown in Figure 14. For both men and women, Crafts and Manual Labor workers had the highest OSHA-recordable event rates. This occupational group also had the highest percentage of men ( 5 percent) and women ( 3 percent) with at least one OSHA event. Technical Support workers had the highest average number of workdays lost or with restricted activity for OSHA events (11 days for men and women combined). We observed no consistent relationship between age and duration of absence among either women or men. No OSHA events were recorded among women in the Service and Power Operator groups.

\section{Diagnostic and Accident Categories for OSHA- Recordable Events}

There were 192 OSHA events recorded in the OSHA 200 Logs, comprised of 48 diagnoses among women and 144 diagnoses among men (Figure 15). Eighty-four percent of the diagnoses reported were for injuries. Sprains and strains, as well as open wounds, were the most common types of OSHArecordable injuries among both men and women.

Figure 15. OSHA-Recordable Diagnoses by Diagnostic Category and Gender

\begin{tabular}{|c|c|c|}
\hline \multirow{2}{*}{ Diagnostic Category } & \multicolumn{2}{|c|}{ Gender } \\
\hline & Women & Men \\
\hline Respiratory & 2 & $\mathbf{0}$ \\
\hline Muscles and Skeleton & 4 & 10 \\
\hline Nervous System & 1 & 5 \\
\hline Skin & 3 & 2 \\
\hline Unspecified Symptoms & 1 & 2 \\
\hline Injury & $\mathbf{3 7}$ & 125 \\
\hline Fractures - Skull & $\mathbf{0}$ & 1 \\
\hline Fractures - Upper Limb & 1 & 4 \\
\hline Fractures - Lower Limb & 2 & 2 \\
\hline Back Sprains and Strains & 5 & 18 \\
\hline Other Sprains and Strains & 4 & 23 \\
\hline Intracranial Injuries & $\mathbf{0}$ & 2 \\
\hline $\begin{array}{l}\text { Open Wounds - } \\
\text { Head, Neck, Trunk }\end{array}$ & 4 & 10 \\
\hline $\begin{array}{l}\text { Open Wounds - } \\
\text { Upper Limb }\end{array}$ & 4 & 21 \\
\hline $\begin{array}{l}\text { Open Wounds - } \\
\text { Lower Limb }\end{array}$ & 1 & $\mathbf{0}$ \\
\hline Superficial Injuries & 4 & 9 \\
\hline Bruises & 1 & 6 \\
\hline $\begin{array}{l}\text { Foreign Bodies Entering } \\
\text { Orifice }\end{array}$ & 0 & 10 \\
\hline Burns & 4 & 16 \\
\hline Unspecified Injuries & 3 & 0 \\
\hline $\begin{array}{l}\text { Adverse Reactions to } \\
\text { Non-Medical Substances }\end{array}$ & 2 & 1 \\
\hline $\begin{array}{l}\text { Adverse Reactions to } \\
\text { External Causes }\end{array}$ & 2 & 2 \\
\hline
\end{tabular}


About 12 percent of the injuries were burns, which occurred primarily among men in the Technical Support and Crafts and Manual Labor occupations. Men in these two occupational groups also sustained most of the open wounds reported. Sprains and strains accounted for 31 percent of all OSHA-recordable injuries in 1996 (35 percent in 1995); open wounds accounted for 25 percent. Conditions related to the muscles and skeleton ( 7 percent) also occurred frequently. Age and occupation did not appear related to the type of accident.

Among the 24 OSHA events not attributed to a particular accident, half of the diagnoses were related to the muscles and skeleton, 19 percent to disorders of the skin, and 15 percent to nervous system disorders. The type of accident was not reported for 129 of the 151 OSHA events that resulted from an accident. Among the 22 OSHA-recordable events that included a description of the accident, the types of accidents reported most often were "submersion/ suffocation/foreign bodies" (Figure 16). The injuries reported most often were "foreign body entering an orifice".

Figure 16. OSHA-Recordable Accidents by Type and Gender

\begin{tabular}{|l|cc|c|}
\hline \multirow{2}{*}{} & \multicolumn{3}{|c|}{ Gender } \\
\cline { 2 - 3 } Accident Category & $\begin{array}{c}\text { Women } \\
\text { Number of } \\
\text { Accidents }\end{array}$ & $\begin{array}{c}\text { Number } \\
\text { Accidents }\end{array}$ \\
\hline $\begin{array}{l}\text { Poisoning- } \\
\text { Non-medicinal }\end{array}$ & 1 & 1 \\
\hline $\begin{array}{l}\text { Natural / } \\
\text { Environmental } \\
\text { Factors }\end{array}$ & 0 & 3 \\
\hline $\begin{array}{l}\text { Submersion/ } \\
\text { Suffocation/ } \\
\text { Foreign Bodies }\end{array}$ & 1 & 0 \\
\hline Other Accidents & 0 & $\mathbf{3}$ \\
\hline Drug Reaction & 2 & 1 \\
\hline
\end{tabular}

\section{Rates of OSHA-Recordable Events}

The rates of all diagnoses combined for OSHA-recordable events by age category, gender, and job category are shown in Figures 17 and 18.

Both men and women aged 50 and older had higher rates than younger workers in the Office Management and Administration group. This age difference was also true for women in the Engineering, Scientific, and Health Care category, and for men in the Nuclear Specialties group. The most striking age difference was observed among women classified as Engineering, Scientific, and Health Care workers, in which workers ages 50 and older had a rate 10 times that of younger women.

Figure 17. OSHA-Recordable Rates by Age and Job Categories, All Diagnoses Combined Among Women

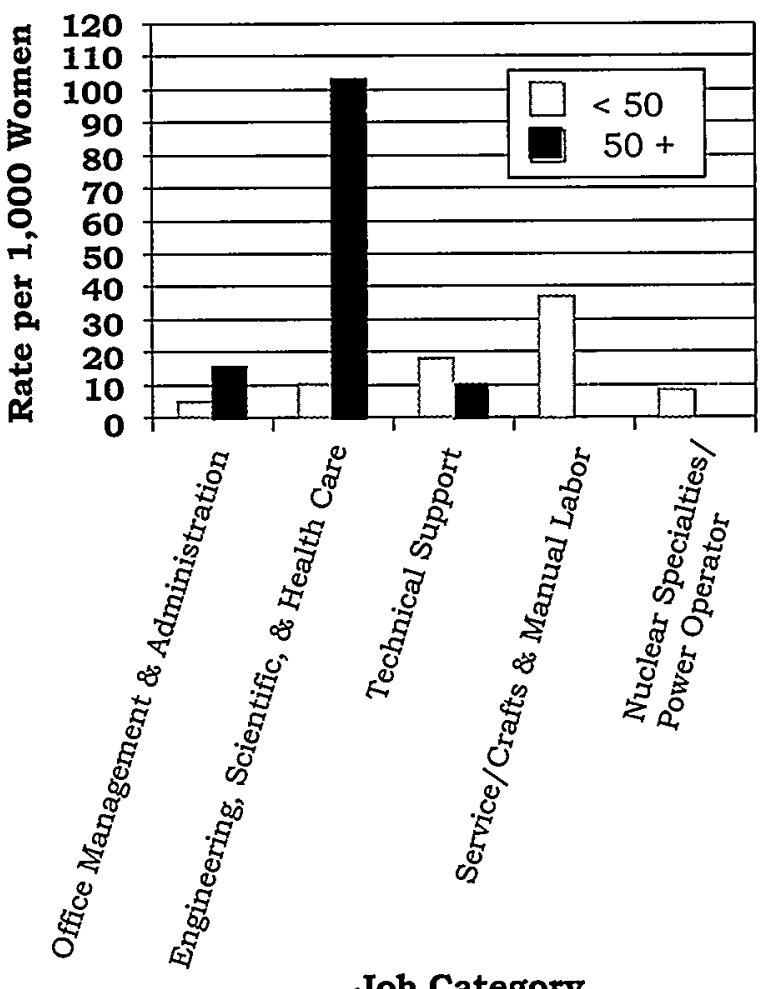

Job Category 
Figure 18. OSHA-Recordable Rates by Age and Job Categories Among Men, All Diagnoses Combined

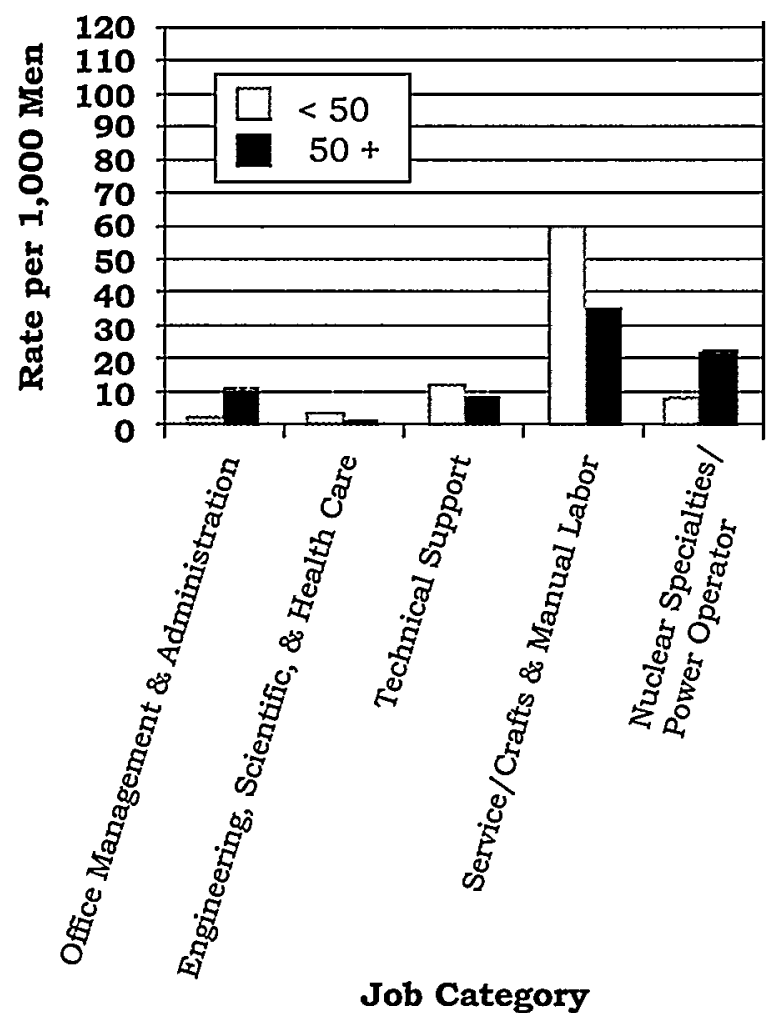

Some of this variation in injury rates for older versus younger workers may reflect the need to combine several occupational groups for analysis due to small numbers of OSHA events in a given occupational category. It is also possible that within a given occupational group men and women may be performing duties with different injury risks. There does not appear to be a consistent relationship between the age of the worker and the risk of occupational injury at Savannah River.

Not all workers were at equal risk for occupational injury. Crafts and Manual Labor workers had an overall occupational injury risk at least 7 times greater than the other occupational groups.

Compared with other workers, Crafts and Manual Labor workers were about 7 times more likely to suffer back sprains and strains; open wounds of the upper limb, head, neck, and trunk; burns; or more likely to report a superficial injury. They were also over 4 times more

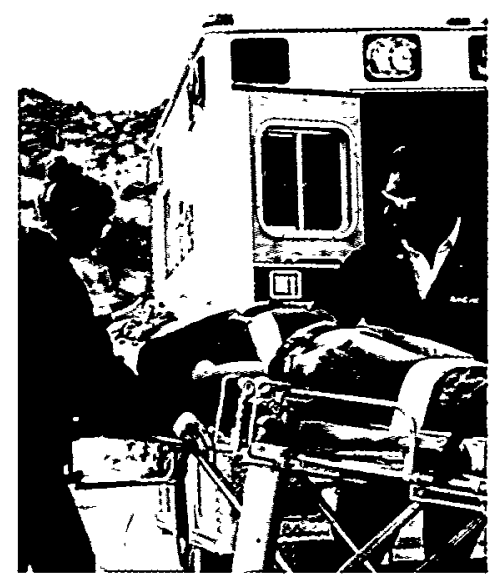
likely to report sprains and strains not affecting the back. The 69 OSHA events among these workers resulted in 442 days of restricted activity and 41 lost workdays, a substantial loss of productivity. Nuclear Specialties workers were almost 6 times more likely than other workers to report conditions affecting the muscles and skeleton.

\section{Time Trends for OSHA-Recordable Events}

Data on OSHA-recordable events were not available for epidemiologic surveillance analysis prior to 1995 . The assessment of time trends requires a minimum of 3 years of data. Time trend analyses for OSHA data will therefore appear in the 1997 Annual Epidemiologic Surveillance Report. 


\section{Glossary}

Adjustment: A mathematical procedure for rates in which the effects of differences of a characteristic (such as age or gender) between groups have been removed. The purpose of adjustment is to allow comparisons between two or more groups with the effect of the differences for the characteristic removed.

Age-Adjusted Rate: A rate that has been mathematically adjusted to account for the effects of differences in the age composition between groups.

Age-Specific Rate: A rate that is calculated for a specific age group (e.g., 16 to 29 years old). Only people in the specific age group are included in the calculation of the rate.

Confidence Interval: A range of values determined by the degree of random variability in the data. The width of the confidence interval is affected by the size of the group being studied and how often the event whose true value is sought occurs. Generally, as the size of the group or the frequency of the event increases, the width of the confidence interval decreases. The level of confidence, for example a 95 percent confidence level, indicates the percentage (e.g., 95 percent) of time that the true value is expected to fall within the confidence interval if the mathematical procedure is repeated 100 times.

Demographics: Characteristics of human populations related to their size, density, age distribution, and vital status.
Diagnosis (diagnoses): Identification of a disease or health condition from signs and symptoms.

Diagnosis Rate: The number of occurrences of a given disease or health condition observed during a given time period per the number of workers at risk of getting that disease during that time period. It is usually multiplied by 100 or 1,000 to produce a rate expressed as a convenient number.

Diagnostic Category: A particular type of disease, a group of related health conditions, or diseases that all affect the same organ system.

Epidemiologic Surveillance: The ongoing evaluation of the health of a human population which is based on the collection and interpretation of demographic and health information for that population.

Epidemiology: The study of the distribution and determinants of diseases and health conditions in human populations.

ICD-9-CM Code: An abbreviation for the International Classification of Diseases, 9th Revision, Clinical Modification. An internationally accepted standardized system for the classification of disease and health data collected from medical records.

OSHA: An acronym for the Occupational Safety and Health Administration.

OSHA Event: An abbreviation used throughout this report for an OSHArecordable event. 
OSHA-Recordable Event: An accident that occurs on the job and involves fatalities (regardless of time between injury and death), time lost from work, transfer of employment, medical treatment other than first aid, loss of consciousness, or restriction of work or motion. Also included is any diagnosed occupational health event reported to the employer that is neither fatal nor results in workdays lost. By law, these events are recordable in the OSHA 200 Log.

Person-Year: A unit of measurement combining the number of people being studied with the time that each was observed equivalent to one. person followed for one year. For example, 5 persons followed for one year contribute five person-years, as do 10 people each followed for half a year.

Relative Risk: The ratio of the occurrence of a disease or health condition in one group compared to the rate of occurrence of that same disease or health condition in another group.

\section{Explanation of Diagnostic Categories}

Throughout this report, health conditions have been grouped into a number of diagnostic categories which come from the International Classification of Diseases, 9th Revision, Clinical Modification (ICD-9-CM). For the text of this report the categories are abbreviated to make the report easier to read. The following table lists the abbreviated categories used throughout the report and the corresponding ICD-9CM codes found in the supporting tables.
Abbreviated Categories Used in the Annual Report

ICD-9-CM Codes

Benign Growths

210-229

235-239

Blood

$280-289$

Cancer

140-208

$230-234$

Digestive

$520-579$

Endocrine / Metabolic

$240-279$

Existing Birth

Conditions

$740-759$

Genitourinary

$580-629$

Heart / Circulatory

$390-459$

Infectious /

Parasites

001-139

Injury

800-999

Miscarriage

$630-676$

Muscles and

Skeleton

710-739

Nervous System

$320-389$

Psychological

290-319

Respiratory

460-519

Skin

680-709

Unspecified Symptoms

780-799 


\section{ICD-9-CM Codes}

\section{All conditions}

Infectious and parasitic diseases

- Intestinal infections

- Tuberculosis

- Zoonotic bacterial diseases

- Other bacterial diseases

- Human Immunodeficiency

Virus (HIV) infection

- Poliomyelitis and other nonarthropod diseases of the central nervous system

- Viral diseases accompanied by exanthem

- Arthropod-borne viral diseases

- Other diseases caused by viruses and chlamydiae

- Rickettsioses and other arthropod-borne diseases

- Other spirochetal diseases

- Mycoses

- Helminthiases
001-V82 All reported health events

001-139 Diseases caused by bacteria, viruses, and parasites

001-009 Infections of the bowel or gut

010-018 TB in the lungs and other organs

020-027 Bacterial diseases that animals transmit to humans

030-041 Whooping cough, diphtheria, strep throat, and gangrene

$042 \quad$ AIDS

045-049 Viral meningitis (swelling of the layers covering the brain and spinal cord); viral encephalitis (swellingofthebrain); and polio

050-057 Diseases accompanied by rashes or blisters like chickenpox, measles, shingles, and herpes

060-066 Encephalitis (swelling of the brain) caused by bites from virus-carrying ticks or mosquitoes

070-079 Viral hepatitis, mumps, rabies, and mononucleosis

080-088 Rocky Mountain spotted fever, malaria, and lyme disease

100-104 Trench mouth and Weil's disease (jaundice caused by coil-shaped bacteria)

110-118 Athlete's foot; fungal infections of fingernails and toenails; and thrush

120-129 Pinworms, tapeworms, roundworms, whipworms 
- Other infectious and parasitic diseases

- Late effects of infectious or parasitic diseases

Malignant neoplasms

- Lip, oral cavity, and pharynx

- Digestive organs and peritoneum

- Respiratory system and intrathoracic organs

- Bone, connective tissue, skin, and breast

- Genitourinary organs

- Other and unspecified sites

- Lymphatic and hematopoietic tissue

- Carcinoma in situ

Benign neoplasms and neoplasms of uncertain behavior and unspecified nature

Endocrine, nutritional, and metabolic diseases and disorders of the immune system

Disorders of the blood and blood forming organs
130-136 Lice, chiggers, scabies, and mites

137-139 Side effects of TB, chickenpox, or polio even though the disease is no longer active

140-208, All cancers, regardless of the part of the body affected 230-234

$140-149$

Lip, mouth, throat, and tongue

150-159 Stomach, esophagus (tube that transports food to the stomach), intestines, colon, rectum, anus, liver, pancreas, and gallbladder

160-165 Sinuses, throat, voice box, lungs, and heart

170-176 Bone, muscle, ligament, tendon, blood vessels, fat, skin, and breast

179-189 Kidney, bladder, and cervix, ovary, uterus, and prostate

190-199 Eye, brain, and thyroid

200-208 Leukemia, lymphoma, Hodgkin's disease, multiple myeloma, lymphosarcoma, and reticulum cell sarcoma

230-234 A cancer that is confined to the site of origin (has not spread to neighboring tissue)

210-229 Tumors that are not cancerous or do not exhibit 235-239 cancerous behavior, regardless of the part of the body affected

240-279 Diseases affecting the hormone secreting glands and organs. Overactive thyroid; underactive thyroid; vitamin deficiency; diabetes; gout; and problems affecting the antibody producing system

280-289 Anemia and hemophilia (excludes leukemia) 
Mental disorders

Diseases of the nervous system and sense organs

- Inflammatory diseases of the central nervous system

- Hereditary and degenerative diseases of the central nervous system

- Other disorders of the central nervous system

- Disorders of the peripheral nervous system

- Disorders of the eye

- Diseases of the ear and mastoid process

Diseases of the circulatory system

- $\quad$ Acute rheumatic fever

- Chronic rheumatic heart disease

- Hypertensive disease
290-319 Psychiatric diagnoses - Non-psychotic disorders: depression; anxiety, fear and stress disorders; alcoholism; drug dependence; and eating disorders, such as anorexia; Psychotic disorders: dementia, schizophrenia, and manic depression

320-389 Huntington's chorea; Alzheimer's and Parkinson's disease; epilepsy; multiple sclerosis; migraine; diseases of the eye, such as cataract and glaucoma

320-326 Bacterial meningitis (swelling of the layers covering the brain and spine); bacterial encephalitis (swelling of the brain); and brain and spinal abscesses

330-337 Alzheimer's and Parkinson's disease, tremors, and Huntington's chorea

340-349 Multiple sclerosis (MS), cerebral palsy, epilepsy, and migraine

350-359 Nerve disorders of the face, carpal tunnel syndrome, muscular dystrophy

360-379 Inflammation and ulcers of the eye and eyelid; detached retina; pink eye; problems with tear ducts; glaucoma; and cataracts

380-389 Infections of the outer, middle, or inner ear; ringing of the ears; hearing loss

390-459 Rheumatic fever, heart murmurs, heart attacks, angina, hardening of the arteries, varicose veins, hemorrhoids, and phlebitis

390-392 High fever and joint pain with possible heart damage

393-398 Long lasting swelling and damage to the heart which results from rheumatic fever

401-405 High blood pressure 
- Ischemic heart disease

(Restricted blood flow

to the heart)

- Diseases of pulmonary circulation

- Other forms of heart disease

- Cerebrovascular disease

- Diseases of the arteries and capillaries

- Diseases of the veins, lymphatics, and other circulatory system diseases

\section{Diseases of the respiratory system}

- Acute respiratory infections

- Other diseases of the upper respiratory tract

- Pneumonia and influenza

- Chronic obstructive pulmonary diseases and allied conditions

- Pneumoconiosis and other lung diseases caused by external agents

- Other diseases of respiratory system
410-414 Heart attack and angina

415-417 Blood clots in the lung and pulmonary aneurysm (bulge that develops in the wall of the pulmonary artery, which is the artery that carries blood to the lungs)

420-429 Swelling of the inner lining, middle lining, or sac enclosing the heart; heart failure; and irregular heartbeat

430-438 Stroke, bleeding in the brain, and blockage or low blood flow in blood vessels of the brain

440-448 Hardening of the arteries; aneurysm (bulge that develops in the walls of arteries); and blood clots

451-459 Phlebitis (swelling of a vein), thrombophlebitis (swelling of a vein which has a blood clot), varicose veins, and hemorrhoids

460-519 Colds, sinusitis, laryngitis, pneumonia, influenza, chronic bronchitis, asthma, and emphysema

460-466 Colds, sore throat, sinus infections, swollen tonsils, and bronchitis

470-478 Allergies, hay fever, sinus infections, bronchitis, and sore throat that continue for a long time

480-487 "The flu" and pneumonia caused by a bacteria or virus

490-496 Emphysema and asthma

500-508 Black lung; miners' asthma; asbestosis; silicosis; berylliosis; and conditions caused by chemical fumes and vapors

510-519 Pleurisy (swelling of the lining of the lungs), collapsed lung, and respiratory failure 


\section{Diseases of the digestive system}

- Diseases of the oral cavity, salivary glands, and jaw

- Diseases of the esophagus, stomach, and duodenum

- Appendicitis

- Hernia of the abdominal cavity

- Non-infectious enteritis and colitis

- Other diseases of the intestines and peritoneum

- Other diseases of digestive system

Diseases of the genitourinary system

- Nephritis, nephrotic syndrome, and nephrosis

- Other diseases of the urinary system
520-579 Diseases affecting the teeth and mouth, salivary glands, digestive tract, and the abdominal cavity. Examples include dental abscess, ulcers, appendicitis, hepatitis (excluding viral hepatitis), cirrhosis of the liver, gallstones, pancreatitis, abdominal hernia, and intestinal polyps

520-529 Tooth problems (too many, too few, abnormal shape or size, cavities, bleeding gums, toothaches), and infections and swelling of the mouth, jaw, and tongue

530-537 Ulcers of the esophagus (tube that transports food to the stomach), stomach, and small intestine; indigestion; and uncontrollable vomiting

540-543 Swelling of the appendix (rupture, surgery, or both may result)

550-553 Ruptures of the groin and diaphragm (muscle which separates the chest area from the lower part of the trunk)

555-558 Crohn's disease and swelling of the intestine and colon

560-569 Irritable bowel syndrome, blockage of the intestine, constipation, and diarrhea

570-579 Diseases of the liver, gallbladder, and pancreas; hepatitis; blood in stool; and bleeding in the stomach and intestine

580-629 Diseases affecting the kidneys, the prostate, and testes; benign breast diseases; infertility (male and female); diseases of the ovary; pelvic inflammatory disease; and menstrual disorders

580-589 Swelling of the kidney; swelling of the small blood vessels in the kidney; and kidney failure

590-599 Swelling and infection of the kidney and bladder; kidney stones; and difficulty urinating 
- Diseases of the male genital organs

- Disorders of the breast

- Inflammatory disease of the female pelvic organs

- Other diseases of the female genital tract

\section{Complications of pregnancy, childbirth, and the puerperium}

- Ectopic and molar pregnancy

- Other pregnancy with abortive outcome

- Complications mainly related to pregnancy

- Normal delivery, and other indications for care in pregnancy, labor, and delivery

- Complications occurring mainly in the course of labor and delivery

- Complications of the puerperium

Diseases of the skin and subcutaneous tissue
600-608 Enlarged prostate; swelling of the scrotum and prostate; and abscess of the prostate

610-611 Benign tumors, cysts, and infections of the breast

614-616 Swelling of the uterus, ovary, fallopian tubes, or cervix

617-629 Conditions associated with menopause and postmenopause; PMS; infertility; and cramps

630-676 Miscarriage; complications of pregnancy, such as hemorrhage; pregnancy-related high blood pressure; preeclampsia; and premature labor or other complications of labor

630-633 Development of fetus outside the uterus and growth of cysts

634-639 Miscarriage and complications associated with miscarriage

640-648 Abnormal bleeding and possible miscarriage; infections; high blood pressure caused by pregnancy; and premature labor

650-659 Delivery requiring little or no assistance; multiple births; breech birth; and problems of the fetus or placenta which affect care of mother

660-669 Long labor; unusually fast delivery; and abnormal bleeding after delivery

670-676 Infections of the breast; blood clot in lung; and varicose veins

680-709 Acne, cellulitis, sunburn, psoriasis, and seborrhea 
- Infections of the skin and subcutaneous tissue

- Other inflammatory conditions of skin and subcutaneous tissue

- Other diseases of the skin and subcutaneous tissue

Diseases of the musculoskeletal system and connective tissue

- Arthropathies and related disorders

- Dorsopathies

- Rheumatism, excluding the back

- Osteopathies, chondropathies, and acquired musculoskeletal deformities

\section{Congenital anomalies}

Certain conditions originating in the perinatal period
680-686 Abscesses, boils, hair-containing cysts, and pus-filled blisters

690-698 Skin rashes caused by detergents, oils, greases, solvents, sun, food, drugs, or medicine

700-709 Corns, calluses, heat rash, swollen hair follicles, acne, and ingrown fingernails and toenails

710-739 Arthritis, systemic lupus erythematosus, ankylosing spondylitis, herniated intervertebral disc ("slipped disc"), lumbago, sciatica, rheumatism, tendonitis, and osteoporosis

710-719 Arthritis; joint pain and stiffness; and other diseases of the connective tissue which supports and connects internal organs, forms bones and blood vessel walls, and attaches to bones

720-724 Swelling of the spine; herniated, slipped and ruptured disc; rheumatoid arthritis of the spine; lumbago; and sciatica

725-729 Swelling and degeneration of joints, muscles, tendons; tennis elbow; and bursitis

730-739 Fracture caused by bone disease; osteoporosis; curvature of the spine; flat foot; hammer toe; and development of deformities of the nose, toes, feet, legs, arms, and hands

740-759 Spina bifida; cleft palate; harelip; and various chromosomal anomalies, such as Klinefelter's syndrome

760-779 Maternal high blood pressure; maternal malnutrition; ectopic pregnancy; breech birth; fetal malnutrition or slow growth; injuries related to birth trauma; and perinatal jaundice 


\section{Symptoms, signs, and \\ ill-defined conditions}

- Symptoms

- Non-specific abnormal findings

- Ill-defined and unknown causes of morbidity and mortality

\section{Injury and poisoning}

- Fractures, all sites

- Dislocations

- $\quad$ Sprains and strains of joints and adjacent muscles

- Intracranial injuries excluding those with skull fractures

- Internal injuries of the thorax, abdomen, and pelvis

- Open wounds
780-799 Blackout, chills, dizziness, fatigue, pallor, abnormal weight loss, undiagnosed chest pain, and heartburn

780-789 Hallucinations, fainting, convulsions, dizziness, fatigue, fever, sleep disturbance, rash, headache, sore throat, chest pain, nausea, vomiting, and heartburn

790-796 Abnormal x-ray, blood, stool, and urine test results

797-799 Senility; asphyxia; respiratory arrest; nervousness; and unexplained death within 24 hours of onset of symptoms

800-999 Dislocation of joints; sprains and strains of associated muscles; concussions; bruises; cuts; internal injuries from crushing, puncture, tearing, or blunt impact; burns; blisters; poisoning; frostbite; heatstroke; and complications of medical or surgical care

800-829 Cracks or breaks of any bone

830-839 Separation of a bone from its normal socket or joint

840-848 Strains are injuries to muscle from overuse or stretching the muscle beyond its normal limit; sprains are injuries involving tearing or overextending the ligaments of a joint

850-854 Concussions; internal bruises; and bleeding within the head without a fracture of the bones of the skull

860-869 Bruising, crushing, tearing, or rupturing the chest, abdomen, and pelvis and the organs within these areas of the body

870-897 Animal bites; cuts; lacerations; punctures; and amputations, excluding the arteries and veins 
- Other injuries and late effects of external causes

Supplementary classifications related to personal or family history of disease

Supplementary classifications related to health care for reproduction and child development

Contact with health services for reasons other than illness or injury
900-999 Miscellaneous injuries, including injuries to the arteries and veins; problems that occur an extended period of time after the injury has taken place ("late effects"); superficial bruises and abrasions; burns; post-injury shock; poisoning; toxic side effects of chemicals; heatstroke; electrocution; and altitude sickness

V10-V19 Covers situations in which the person is not ill or injured but has a personal or family history of problems, such as cancer, mental illness, allergies, or arthritis that may affect his or her risk of illness

V20-V28 Problems related to pregnancy, postpartum care, contraception, outcome of delivery, and physical development of child

V50-V59 Care for workers who have been treated previously for an illness or injury that is no longer present but who receive care to complete treatment or prevent recurrence 